\title{
O custo da política subnacional: a forma como o dinheiro é gasto importa? Relação entre receita, despesas e sucesso eleitoral
}

\author{
Jeison Giovani Heiler \\ João Paulo Saraiva Leão Viana \\ Rodrigo Dolandeli dos Santos
}

\section{Introdução $^{1}$}

Nos últimos anos ampliou-se o número de estudos sobre o efeito do dinheiro nas eleições. As pesquisas nesse campo especializaram-se em variadas perspectivas analíticas, tais como: a distribuição do horário gratuito de propaganda eleitoral (HGPE) entre os candidatos, os padrões e doações do empresariado e segmentos econômicos, a relação entre emendas parlamentares e contratos públicos, e a influência das pesquisas eleitorais no investimento realizado pelos financiadores de campanhas (Mancuso, 2015).

No entanto, boa parte do debate, não somente acadêmico, circunscreve-se ao aspecto normativo do fenômeno. De tal modo que a influência do poder econômico torna-se o lugar-comum do problema, desdobrando-se na maioria das vezes na questão de as empresas, por serem as maiores fontes de financiamento, participarem ou não das eleições.

Neste artigo não nos atemos a essa controvérsia. Embora, igualmente, não nos privemos de considerar que compreender as doações empresariais como as únicas determinantes do desequilíbrio na política seja uma limitação às análises empíricas. Haja vista que características fundamentais dos competidores poderiam ser deixadas de lado para entender o processo político.

Uma vez que as pesquisas sobre financiamento de campanha têm se ocupado da receita, a perspectiva assinalada acima nos aponta a necessidade de investigar como os candidatos gastam os seus recursos. Em outras palavras, ao deixarmos de investigar, exclusivamente, as causas da assimetria entre os competidores através da arrecadação, presumimos existir conexão indispensável entre as características dos candidatos e a

\footnotetext{
1 Agradecemos aos pareceristas anônimos pelas excelentes sugestões. Este artigo foi apresentado em versão anterior com o título "Financiamento do sistema partidário e eleitoral nas democracias contemporâneas", no $38^{\circ}$ Encontro Anual da Anpocs. Todos os eventuais problemas e erros são de nossa inteira responsabilidade.
} 
forma como o dinheiro é gasto.

Portanto, o foco deste artigo não será a análise da entrada dos recursos (receita), mas sim a saída (despesa). Embora os estudos demonstrem uma forte correlação entre dinheiro e voto, consideramos igualmente factível que a maneira como esses recursos são utilizados nos ofereça evidências necessárias para compreender de forma mais detalhada essa associação.

Dadas as circunstâncias da competição eleitoral, as duas questões principais deste artigo são:

a) a forma como os atores utilizam seus recursos expressa as particularidades dos competidores?

b) determinados gastos de campanha possuem maior impacto no sucesso eleitoral do que outros?

Dividimos este artigo em três partes. Na primeira seção, "Debate bibliográfico", fazemos um breve debate teórico sobre o tema, enfocando a característica recente dos estudos sobre o dinheiro na campanha e seu perfil analítico empírico. Na segunda, "Hipóteses e metodologia", apresentamos nossas variáveis, bem como o método de pesquisa. Na última, "A despesa de campanha em 2010", apresentamos os resultados encontrados nos testes realizados.

\section{Debate bibliográfico}

As pesquisas sobre financiamento de campanha tendem, metodologicamente, a compreender o dinheiro ora como uma variável explicativa, ora como variável dependente. Mancuso (2015) retrata bem esse cenário ao sintetizar as principais discussões da área: (i) a relação entre investimentos e resultado eleitoral; (ii) a relação entre investimentos eleitorais e benefício para os financiadores; e (iii) os determinantes do financiamento eleitoral (Mancuso, 2015, p. 4). As duas primeiras abordagens tratam de como o dinheiro explicaria tanto o sucesso do candidato quanto o comportamento dos políticos no processo decisório. E o terceiro ponto assinalado pelo autor ressalta as variáveis que podem explicar o financiamento dos candidatos, como, por exemplo, a força do candidato ou interesse do setor econômico (Jacobson, 1978; Santos, 2012).

De todo modo, há praticamente um consenso entre os pesquisadores brasileiros sobre a profunda influência do dinheiro no resultado das eleições. Isso seria comprovado pela maioria dos estudos que apontam para uma associação significativa e positiva entre recursos recebidos, principalmente provenientes de pessoas jurídicas, e sucesso eleitoral (Mancuso e Speck, 2013; Samuels, 2001; Samuels, apud Mancuso, 2015). Ainda nessa área, as análises sobre como as doações de campanha resultam em benefícios para os financiadores encontram evidências significativas de que o financiamento eleitoral por 
parte de empresas favorece o acesso destas aos recursos públicos (Claessens, Feijen e Laeven, 2008; Lazzarini et al., 2011) ${ }^{2}$.

Apesar de a maioria dos estudos retratarem as arenas políticas, há também pesquisas que sinalizam a necessidade de observar fatores econômicos e sociais. Até mesmo porque muito pouco se conhece acerca das estratégias de investimentos dos grandes doadores de campanhas eleitorais no país (Mancuso, 2015).

Outro aspecto retratado no debate acadêmico e de particular interesse ao que trabalhamos neste artigo é o encarecimento das campanhas no Brasil nos últimos anos ${ }^{3}$. Sabemos que muitas podem ser as interpretações a esse respeito, como, por exemplo, o aperfeiçoamento e a institucionalização do Sistema de Prestação de Contas Eleitorais (SPCE) do Tribunal Superior Eleitoral (TSE). Nesse caso, em face do maior poder de fiscalização do TSE, o dinheiro que antes não era contabilizado nas prestações de contas estaria gradativamente "incorporando-se" à contabilidade oficial, constrangendo a prática do caixa 2.

Uma abordagem diferente desta última guardaria referência à intensidade da disputa eleitoral nos últimos pleitos. Ou seja, à medida que a carreira política tem ficado cada vez mais profissionalizada, o acirramento da competição se intensifica e, consequentemente, o custo das campanhas se eleva. Mais do que isso, a crença dos políticos no fato de que o dinheiro implicaria diretamente em voto também refletiria em uma "corrida armamentista por recursos" (Duschinsky, 2002), ou seja, uma disputa cada vez maior entre os candidatos por financiamento de campanha.

No entanto, para além da elevação dos gastos, a concentração dos recursos poderia ser entendida como evidência maior da assimetria econômica entre os competidores, visto que a maior parte do dinheiro na política fica restrita a poucos atores, incluindo doadores e candidatos beneficiados (Speck, 2012, p. 75) ${ }^{4}$. Desse modo, não somente o volume investido nas campanhas deveria ser considerado como um dos

\footnotetext{
2 Mancuso (2015) menciona outros estudos nessa perspectiva. Rocha (apud Mancuso, 2015) abordou a relação entre os financiamentos do BNDES e o financiamento eleitoral de empresas ao comitê do PT na eleição presidencial de 2010, observando que muitas dessas empresas foram contempladas entre os anos de 2008 e 2010 com recursos do BNDES. Mesmo assim, devido ao baixo coeficiente de determinação, o autor preferiu não indicar a existência de causalidade nessa relação. Boas, Hidalgo e Richardson (apud Mancuso, 2015) apontaram para associação positiva e estatisticamente significativa entre os financiadores dos candidatos do PT à Câmara Federal nas eleições de 2006 e o volume de contratos firmados por esses empresários com o governo federal nos meses seguintes, o que viria a corroborar a hipótese apresentada por Samuels (apud Mancuso, 2015) de que as emendas parlamentares seriam uma forma de moeda de troca entre parlamentares e financiadores. Entretanto, ao estudar os contratos gerados por emendas do orçamento pelos 70 deputados federais paulistas, no estado de São Paulo, nos anos de 2002 e 2006 , Mezzaranna (apud Mancuso, 2015) não encontrou nenhum contrato que beneficiasse os autores das emendas.

${ }^{3}$ Segundo o TSE, no pleito de 2010 o investimento financeiro aproximou-se dos 3 bilhões de reais. Desse total, quase $75 \%$ era proveniente de empresas privadas, sendo que $32,5 \%$ dos recursos tinham origem em um número reduzido de 15 doadores, entre grandes empresas e grupos empresariais.

${ }^{4}$ De acordo com Bruno Speck "a política é financiada por poucos atores, e as empresas são responsáveis por mais da metade do volume de recursos, provenientes de um grupo muito restrito de doadores" (Speck, 2012, p. 75). O autor ressalta que em 2012 aproximadamente 18 mil empresas doaram recursos no Brasil, das quais mais de $50 \%$ das doações situam-se na faixa de $R \$ 1$ mil a $R \$ 100$ mil. Além disso, 2 mil empresas doaram mais de 100 mil reais, e apenas 64 empresas doaram mais de 10 milhões de reais.
} 
principais fatores a serem pesquisados no Brasil, mas essencialmente a concentração dos recursos.

No âmbito do debate sobre modelos possíveis de financiamento de campanha, tanto a elevação dos gastos em campanhas quanto a concentração econômica surgem como provas irrefutáveis para justificar a proibição de doações para campanha pelas empresas. Nesse sentido, uma perspectiva do financiamento exclusivamente público nos remeteria ao protagonismo da organização partidária na gestão dos recursos e repasses aos candidatos. Porém, em face das propostas conhecidas, somos obrigados a reconhecer que tal medida não afetaria substancialmente, pelo menos, a dimensão da concentração de recursos em poucos atores.

É importante salientar a transformação dos padrões de doações empresariais nas eleições que já vivenciamos, especialmente para as eleições proporcionais. Se compararmos os pleitos de 2002, quando o TSE disponibilizou a prestação de contas de maneira mais sistematizada, com as últimas eleições, vemos claramente que os candidatos já dependem menos de doações diretas das empresas. Isso significa que os partidos políticos vêm recebendo a maior parte dos recursos nas campanhas, redistribuindo-os a candidatos e comitês, e nem por isso se alterou o quadro de concentração de recursos em poucos atores ${ }^{5}$.

Ou seja, a conjunção entre maior profissionalização das carreiras e aumento da centralidade do partido na distribuição dos recursos de campanha, situação essa que não se alterará por meio de um financiamento exclusivamente público, leva-nos à necessidade de investigar os padrões de despesas dos candidatos. Assim, poderemos compreender se certos aspectos e características dos competidores, capazes de inferir diferentes níveis de profissionalização, poderiam ser evidenciados nos gastos de campanha. Essa questão será detalhada nas próximas seções, na qual buscaremos dialogar com as abordagens da literatura levantadas até o momento.

\section{Hipóteses e metodologia}

Nesta seção apresentamos as variáveis com as quais trabalhamos no artigo, começando pela categorização dos gastos de campanha das eleições para deputado federal de 2010. Na Tabela 1 segmentamos as despesas dos candidatos em cinco grandes blocos: "comunicação e publicidade"; "infraestrutura"; "gastos com pessoal"; "doações a outros candidatos e também partidos"; e "outros gastos não especificados".

5 Além disso, pensando nos critérios de repartição dos recursos públicos destinados atualmente aos partidos, também podemos pensar em concentração na distribuição do Fundo Partidário (Fundo Especial de Assistência aos Partidos Políticos). A Lei no 11.459, de 21 de março de 2007, alterou o percentual de distribuição do fundo entre os partidos: $95 \%$ dos recursos são repartidos proporcionalmente entre as legendas que tiveram o mínimo de $5 \%$ dos votos apurados na última eleição para a Câmara dos Deputados, distribuídos em pelo menos um terço dos estados, com um mínimo de $2 \%$ do total em cada um deles. Os restantes $5 \%$ dos recursos do Fundo Partidário são distribuídos entre todos os demais partidos que tenham estatutos registrados no TSE. 
Procuramos categorizar esses gastos de acordo com o entendimento básico acerca do funcionamento das campanhas eleitorais. Embora seja um agrupamento arbitrário, tentamos coincidir, intuitivamente, as despesas da maneira mais aproximada possível. Da mesma forma, reconhecemos que determinadas despesas, por mais que estejam separadas por blocos distintos, podem ter conexão direta entre si. Gastos com "transporte ou deslocamento", por exemplo, podem ter relação imediata com "eventos de promoção da candidatura", ou até mesmo com "despesas com pessoal", mesmo estando em blocos distintos. Outro aspecto é que provavelmente os critérios de prestação de contas sejam muito variáveis entre as candidaturas. As despesas que presumimos serem comparáveis, na realidade, podem ter sido realizadas para eventos de campanhas de natureza diferente. Entretanto, a despeito de possíveis riscos de fidedignidade dos dados, consideramos que o Sistema de Prestação de Contas Eleitorais (SPCE) fornece as informações mais completas para a pesquisa sobre as doações de campanhas no país. A exemplo dos estudos sobre a receita dos candidatos que se deparam com o caixa 2 , as pesquisas sobre as despesas igualmente devem considerar as possíveis omissões de informação.

\section{Tabela 1}

Gastos de campanha categorizados. Eleição de 2010

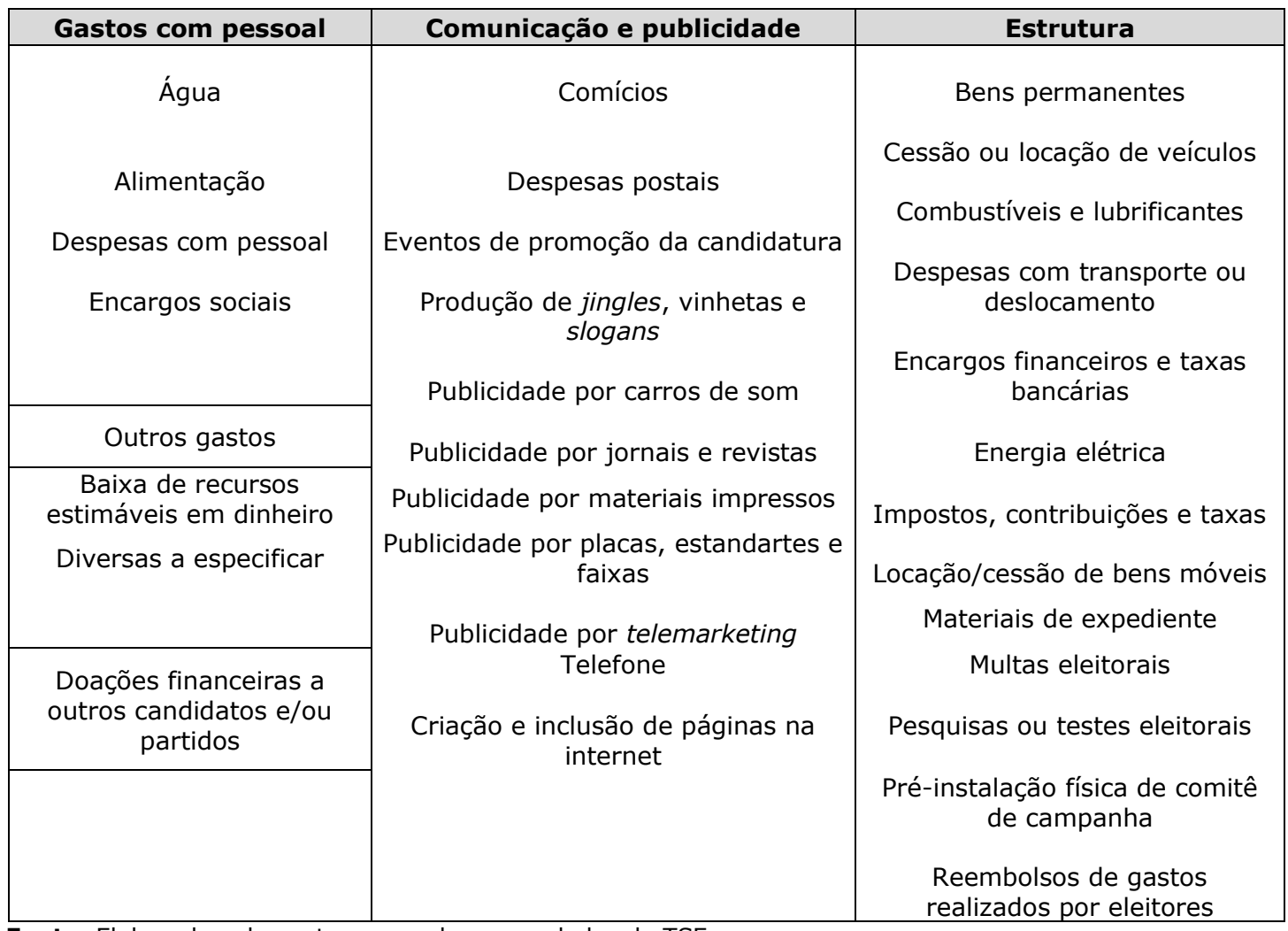

Fonte: Elaborada pelos autores com base nos dados do TSE. 
Nesse sentido o maior problema se refere à categorização de "outros gastos". Somente para deputado federal, por exemplo, vimos que $25 \%$ da despesa dos eleitos e $27 \%$ da dos não eleitos foram classificadas como "outros gastos", conforme nos mostra o Gráfico 1 (p. 63). Esse dado nos mostra que as campanhas, por mais que tenham se profissionalizado, ainda carecem de uma estrutura mais transparente. Sendo esse um fator característico predominante, especialmente entre os candidatos mais fortes eleitoralmente.

No bloco de despesas com "comunicação e publicidade" agregamos desde os gastos mais elaborados como, por exemplo, "produção de jingles" até a "publicidade em placas". Procuramos verificar aqui como se distribui esse tipo de gasto tendo em vista a presumível demanda por comunicação em carreiras mais profissionalizadas. Não é à toa que a pauta comum em toda eleição é a disputa por tempo na TV visando ao horário gratuito de propaganda eleitoral (HGPE), o que impacta sensivelmente na dinâmica de composição de alianças.

Outro bloco de despesas categorizado foi o de "estrutura". Aqui, consideramos que os gastos indicam a força organizacional do candidato e sua capacidade de coordenação dos eventos da campanha. De certa forma, poderíamos inferir que candidatos com maiores gastos em "estrutura" estariam mais propícios a uma boa performance eleitoral.

O bloco de despesas com "pessoal" agrega os gastos com cabos eleitorais, alimentação e afins. Tais despesas indicariam a necessidade de mobilização de militância e apoiadores, embora possa haver variação dessa demanda se se considera a característica dos candidatos. Ou seja, políticos mais envolvidos com grupos sociais organizados poderiam depender menos desse tipo de despesa, bem como candidatos de partidos mais à esquerda do espectro ideológico. Nesse raciocínio, políticos com gastos exacerbados nessa área poderiam indicar um viés clientelista de suas campanhas.

Por último, classificamos em um único grupo as despesas realizadas com "doações a outros candidatos, comitês e partidos". Esse tipo de gasto poderia ser considerado um indicador da força política do candidato dentro de sua organização. Em muitos casos, incumbents financiam candidatos, inclusive de outros partidos, "realocando" recursos. O que, consequentemente, confere a esse candidato um papel mais amplo na coligação.

Feita a categorização da principal fonte de dados utilizada neste artigo, tratamos de apresentar nossas duas hipóteses de pesquisa:

H1: O volume de gastos em "estrutura" e "comunicação" seriam os maiores determinantes do sucesso eleitoral dos candidatos.

$\mathrm{H} 2$ : Candidatos que concentram recursos em apenas um tipo de gasto teriam menor probabilidade de ser eleitos.

Neste artigo, utilizamos técnicas de regressão logística multivariada para testar o impacto dos tipos de despesa no sucesso eleitoral dos candidatos. Em face da 
característica da variável dependente, utilizamos o modelo binário logístico para mensurar a diferença em termos de razão de chances de que determinados padrões de gastos resultem em maior ou menor probabilidade de êxito eleitoral. Além disso, empreendemos análises descritivas com a variável "votos" categorizada em quartis de forma a possibilitar uma análise do tema de forma a superar os limites da abordagem dicotômica: eleito/não eleito. Dessa forma é possível comparar distintos padrões de gastos entre candidaturas com uma votação mais baixa e candidaturas mais bem votadas, embora não eleitas, por outros fatores tais como quociente eleitoral ou nominatas muito fortes dentro de um determinado partido, por exemplo. Também testamos as hipóteses deste artigo através da análise de regressão linear na qual as variáveis votos e despesas são utilizadas de forma contínua tal como se apresentam naturalmente. Procuramos levar em conta a magnitude do colégio eleitoral, guardando relação com suas particularidades políticas e socioeconômicas, como filiação e organização partidária, incumbência, e carreira política e ocupação social. Os dados observados referem-se à prestação de contas dos candidatos a deputado federal na eleição de 2010.

\section{A despesa de campanha em 2010}

Nesta seção fazemos uma descrição geral do financiamento de campanha para deputado federal na eleição de 2010. Em seguida, descrevemos as variáveis que serão testadas no modelo de regressão logística.

Ao observarmos os dados do financiamento (Gráfico 1), mesmo não ponderados por unidade federativa (UF), vemos que os candidatos eleitos, comparados aos não eleitos, declararam no conjunto de dados uma variação de $5 \%$ para mais em suas despesas com "pessoal". Em contrapartida, investiram 5\% menos em "publicidade e comunicação". Porém, para eleitos e não eleitos, os gastos com "comunicação e publicidade" foram os maiores em comparação aos outros tipos de despesas.

Como vemos no Gráfico 1, a similitude nas porcentagens entre eleitos e não eleitos, a princípio, poderia reduzir o peso do argumento sobre a importância da forma como os gastos são distribuídos. Porém, esses valores, quando ponderados pela disputa dentro do distrito eleitoral, reforçam o impacto que determinadas despesas possuem sobre o resultado eleitoral. Por isso, é importante observar, por exemplo, que em valores absolutos as despesas com "estrutura" são bem menores que as outras, mas no teste de regressão logística, que será descrito adiante (Tabela 17, p. 83), esse tipo de gasto demonstrou ser mais determinante que as outras despesas. 
Gráfico 1

\section{Distribuição percentual de despesas por resultado eleitoral Deputados federais}

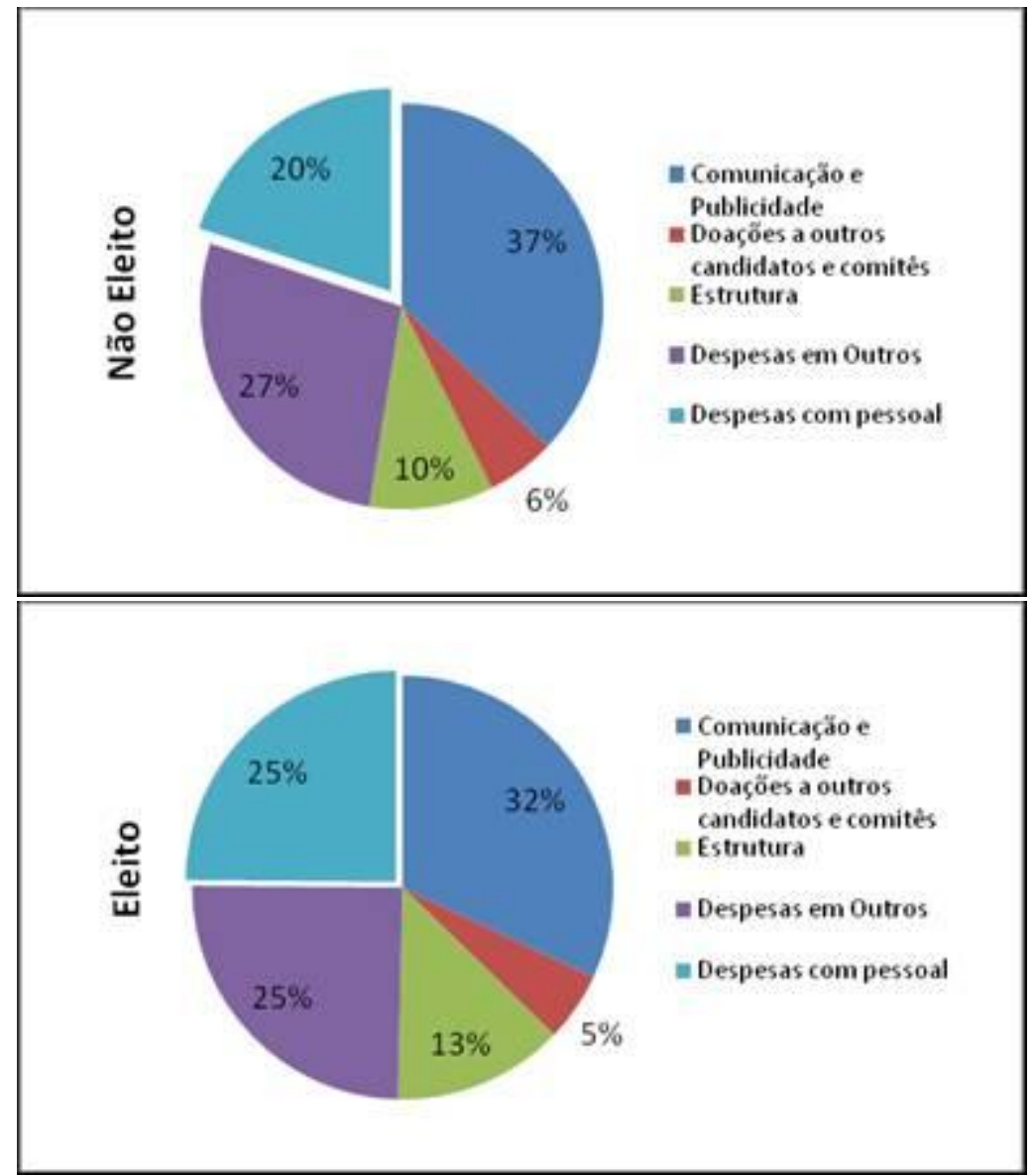

Fonte: Gráfico elaborado pelos autores com base nos dados do TSE.

Outra forma de apreender a variação da forma como se dá o emprego dos recursos é ponderar pela votação agregada em quartis. A Tabela 2 informa que, dentre os candidatos mais votados ( $4^{\circ}$ quartil), "comunicação" foi o principal tipo de despesa $(35,7 \%)$, seguida das "despesas com pessoal" (26\%): 
Tabela 2

Distribuição percentual de despesas por votação em quartis

\begin{tabular}{|l|c|c|c|c|}
\hline \multirow{2}{*}{ Despesa } & \multicolumn{4}{|c|}{ Votos por quartis } \\
\cline { 2 - 5 } & $\mathbf{\mathbf { 1 } ^ { \mathbf { 0 } } \text { quartil }}$ & $\mathbf{2}$ quartil & $\mathbf{3 0}^{\mathbf{0}}$ quartil & $\mathbf{4 0}^{\mathbf{0}}$ quartil \\
\cline { 2 - 5 } & $\mathbf{\%}$ média & $\mathbf{\%}$ média & \% média & \% média \\
\hline Comunicação & 16,2 & 25,8 & 24,6 & 35,7 \\
\hline Doações & 13,9 & 10,4 & 28,2 & 16,2 \\
\hline Estrutura & 10,4 & 9,5 & 10,9 & 13,1 \\
\hline Outras & 30,6 & 24,1 & 14,9 & 9,0 \\
\hline Pessoal & 28,9 & 30,2 & 21,4 & 26,0 \\
\hline Total & $\mathrm{R} \$ 17.339,92$ & $\mathrm{R} \$ 23.400,81$ & $\mathrm{R} \$ 117.536,92$ & $\mathrm{R} \$ 940.602,30$ \\
\hline
\end{tabular}

Fonte: Elaborada pelos autores com base em dados do TSE.

Na Tabela 3 vemos que os candidatos de partidos mais à esquerda no espectro ideológico concentraram menos gastos percentualmente em despesas com "pessoal". O PSTU não teve qualquer despesa com "pessoal", o PSOL teve apenas $4 \%$ do total de gastos declarados, PCB $8 \%$, PDT $15 \%$, PSB e PCdoB $20 \%$ e PT $22 \%$.

Por sua vez os partidos de direita foram os que, nessa rubrica, mais empregaram recursos: PMN 36\%, PPS 33\%, PTdoB 30\%, PR 29\%, PSDB, PP, DEM 28\%. As diferenças tornam-se expressivas quando tomadas à luz do valor final de recursos que representam. Em números absolutos os candidatos do PSDB concentraram o maior volume de recursos nesse tipo de despesa com R\$ 97 milhões, seguido do PMDB com R\$ 84 milhões e do PT com R\$ 54 milhões. Portanto, os dados reforçariam a inferência de que candidatos de partidos mais à esquerda, em tese, gastariam menos recursos com "pessoal".

No entanto, os partidos mais à esquerda apresentaram altas taxas de despesas classificadas como "outros": o PSTU com $84 \%$ e o PCO com 52\%.

Tabela 3

Distribuição de despesas por partido (\%)

\begin{tabular}{|l|c|c|c|c|c|c|c|}
\hline Partido & $\begin{array}{c}\text { Despesas } \\
\text { em outros }\end{array}$ & $\begin{array}{c}\text { Despesas } \\
\mathbf{e m} \\
\text { estrutura }\end{array}$ & $\begin{array}{c}\text { Doações a } \\
\text { candidatos } \\
\text { e comitês }\end{array}$ & $\begin{array}{c}\text { Comunicação } \\
\text { e publicidade }\end{array}$ & Pessoal & $\begin{array}{c}\text { Despesas } \\
\text { totais R\$ }\end{array}$ & $\begin{array}{c}\text { \% total } \\
\text { despesas }\end{array}$ \\
\hline PSDB & 25 & 12 & 4 & 30 & 28 & $342.499 .862,58$ & 20,6 \\
\hline PMDB & 11 & 15 & 6 & 42 & 26 & $322.924 .887,63$ & 19,4 \\
\hline PT & 9 & 14 & 9 & 46 & 22 & $247.780 .594,15$ & 14,9 \\
\hline PSB & 28 & 12 & 3 & 38 & 20 & $148.611 .590,33$ & 8,9 \\
\hline DEM & 13 & 15 & 7 & 38 & 28 & $102.832 .846,81$ & 6,2 \\
\hline PDT & 38 & 10 & 7 & 31 & 15 & $88.994 .052,65$ & 5,4 \\
\hline PP & 16 & 14 & 8 & 34 & 28 & $84.213 .320,90$ & 5,1 \\
\hline PR & 10 & 17 & 6 & 38 & 29 & $83.334 .860,31$ & 5,0 \\
\hline PTB & 16 & 14 & 5 & 38 & 27 & $54.454 .196,53$ & 3,3 \\
\hline
\end{tabular}


JEISON GIOVANI HEILER; JOÃO PAULO SARAIVA LEÃO VIANA; RODRIGO DOLANDELI DOS SANTOS

\begin{tabular}{|c|c|c|c|c|c|c|c|}
\hline Partido & $\begin{array}{l}\text { Despesas } \\
\text { em outros }\end{array}$ & $\begin{array}{c}\text { Despesas } \\
\text { em } \\
\text { estrutura }\end{array}$ & $\begin{array}{c}\text { Doações a } \\
\text { candidatos } \\
\text { e comitês }\end{array}$ & $\begin{array}{l}\text { Comunicação } \\
\text { e publicidade }\end{array}$ & Pessoal & $\begin{array}{l}\text { Despesas } \\
\text { totais R\$ }\end{array}$ & $\begin{array}{l}\text { \% total } \\
\text { despesas }\end{array}$ \\
\hline PPS & 21 & 15 & 4 & 26 & 33 & $37.324 .512,71$ & 2,2 \\
\hline PV & 15 & 14 & 3 & 44 & 24 & $33.751 .402,26$ & 2,0 \\
\hline PSC & 12 & 13 & 8 & 43 & 23 & $26.260 .142,29$ & 1,6 \\
\hline PCdoB & 17 & 14 & 7 & 42 & 20 & $25.814 .408,88$ & 1,6 \\
\hline PMN & 12 & 18 & 2 & 31 & 36 & $25.047 .946,11$ & 1,5 \\
\hline PRB & 32 & 11 & 1 & 44 & 12 & $7.881 .003,69$ & 0,5 \\
\hline PSL & 34 & 8 & 4 & 26 & 28 & $7.034 .591,60$ & 0,4 \\
\hline PHS & 30 & 12 & 0 & 34 & 24 & $5.108 .079,50$ & 0,3 \\
\hline PTC & 21 & 12 & 2 & 37 & 28 & $4.011 .809,67$ & 0,2 \\
\hline PTdoB & 40 & 9 & 0 & 22 & 30 & $3.727 .041,43$ & 0,2 \\
\hline PSOL & 31 & 5 & 2 & 58 & 4 & $2.347 .860,52$ & 0,1 \\
\hline PSDC & 42 & 10 & 0 & 26 & 22 & $2.329 .987,26$ & 0,1 \\
\hline PRTB & 32 & 8 & 0 & 47 & 13 & $1.569 .991,15$ & 0,1 \\
\hline PRP & 36 & 10 & 1 & 29 & 24 & $1.510 .891,22$ & 0,1 \\
\hline PTN & 29 & 15 & 0 & 44 & 12 & $1.157 .592,82$ & 0,1 \\
\hline PSTU & 84 & - & - & 16 & 0 & $300.558,23$ & 0,0 \\
\hline PCB & 34 & 15 & 0 & 42 & 8 & $101.175,61$ & 0,0 \\
\hline PCO & 52 & - & - & 48 & - & $10.327,00$ & 0,0 \\
\hline Total & 27,4 & 12,0 & 3,6 & 36,8 & 21,7 & $\begin{array}{c}1.660 .935 .533 \\
84 \\
\end{array}$ & 100,0 \\
\hline D-P & 0,157768214 & 0,04 & 0,03 & 0,09 & 0,09 & $94.885 .852,39$ & 0,06 \\
\hline CV & 1,737194504 & 3,16 & 1,21 & 4,05 & 2,47 & 17,5 & 17,5 \\
\hline
\end{tabular}

Fonte: Elaborada pelos autores com base em dados do TSE.

Ao observarmos o "coeficiente de variação" (CV) das despesas de todos os partidos, verificamos que os gastos com "comunicação e publicidade" e com "estrutura" foram os que mais variaram, com os respectivos valores de 4,05 e 3,16. De acordo com esses coeficientes, ambos os gastos foram os mais heterogêneos, indicando padrões muito distintos de profissionalização das campanhas entre os partidos.

Ainda observando a distribuição de gastos entre os partidos, consideramos a classificação proposta por Fernando Guarnieri (2011) a respeito do grau de organização e controle dos partidos por suas lideranças. O autor fornece uma nova tipologia para superar a clássica divisão dicotômica entre partidos de massa organizados e capazes de impor disciplina a seus membros e partidos não institucionalizados altamente fragmentados e baseados em vínculos pessoais. Para Guarnieri, "No Brasil os partidos mais organizados não são necessariamente os mais coesos e os partidos menos organizados são aqueles nos quais as lideranças têm maior poder" (2011, p. 254). Dessa forma classifica os partidos em "Organizados/Poliárquicos" (PT, PMDB), partidos "De organização Mista/Oligárquicos" (PSDB, PDT, DEM) e partidos Organizados/Monocráticos 
$(\mathrm{PTB} / \mathrm{PP})^{6}$. Testamos se essa classificação proposta por Guarnieri tem efeitos sobre a forma de distribuição das despesas dos candidatos inserindo essa variável nas análises de regressões logística e linear, os resultados para esses testes são apresentados e discutidos mais adiante. Na Tabela 4 apresentamos a distribuição média das despesas quando considerada a tipologia proposta pelo autor. Além disso, a tabela ilustra a distribuição de acordo com a faixa de votos dos candidatos por quartis e conforme a magnitude do colégio eleitoral.

Observando a Tabela 4 com esse foco, entretanto, as médias pouco diferem entre os partidos considerando a classificação proposta por Guarnieri. Nota-se, porém, que as despesas em "comunicação" são as mais comuns dentre os candidatos situados nos maiores quartis de votos, independentemente da força do partido e da magnitude dos distritos eleitorais.

De acordo com Guarnieri, quando as lideranças partidárias não têm controle direto sobre as decisões do partido, tendo que se submeter à vontade da maioria, a probabilidade de lançar candidatos, quando o partido não tem chance, é próxima a $60 \%$. Já quando as decisões partidárias estão nas mãos das lideranças, a probabilidade de lançar um candidato sem chance cai pela metade, ficando próxima a $25 \%$. O autor destaca ainda que, quando um partido tem chance de vitória, a probabilidade de entrar na disputa fica em torno de $60 \%$ em partidos centralizados enquanto em partidos descentralizados isso ocorre em mais de $80 \%$ das vezes (2011, p. 251). Assim seria de esperar que em partidos mais centralizados e organizados a concentração de despesas variasse entre candidatos de acordo com a votação obtida, espelhando o fato de que, estatisticamente, lançam menos candidatos sem chances de sucesso.

\footnotetext{
6 Resumidamente, de acordo com Guarnieri (2011, p. 247), "Os partidos monocráticos e oligárquicos (PSDB, PDT, PTB, DEM e PP) são organizações fortes porque suas lideranças controlam os processos decisórios no interior do partido, decidindo como se darão a seleção de candidatos e a decisão de participar ou não de disputas eleitorais. As lideranças nos partidos poliárquicos (PT, PMDB) têm maiores dificuldades em controlar as decisões em seu interior, o que, como veremos a seguir, tem implicações diretas na estratégia eleitoral adotada por eles".
} 
Tabela 4

Distribuição média das despesas segundo a votação por quartis, de acordo com a força do partido e a magnitude do colégio eleitoral (\%)

\begin{tabular}{|c|c|c|c|c|c|c|c|c|c|c|c|c|c|}
\hline & \multirow{5}{*}{ Despesas } & \multicolumn{12}{|c|}{ Magnitude colégio eleitoral } \\
\hline & & \multicolumn{4}{|c|}{ Alta } & \multicolumn{4}{|c|}{ Média } & \multicolumn{4}{|c|}{ Baixa } \\
\hline & & \multicolumn{4}{|c|}{ Votos por quartis } & \multicolumn{4}{|c|}{ Votos por quartis } & \multicolumn{4}{|c|}{ Votos por quartis } \\
\hline & & $1^{\circ} Q$ & $2^{\circ} Q$ & $3^{\circ} Q$ & $4^{\circ} Q$ & $1^{\circ} Q$ & $2^{\circ} Q$ & $3^{\circ} \mathrm{Q}$ & $4^{\circ} Q$ & $1^{\circ} Q$ & $2^{\circ} Q$ & $3^{\circ} Q$ & $4^{\circ} Q$ \\
\hline & & Mean & Mean & Mean & Mean & Mean & Mean & Mean & Mean & Mean & Mean & Mean & Mean \\
\hline \multirow{5}{*}{$\begin{array}{l}\text { Poliárquicos/ } \\
\text { Organizados }\end{array}$} & Comunicação & 13,8 & 17,8 & 39,3 & 36,1 & 16,5 & 27,6 & 37,7 & 42,5 & 14,9 & 0,0 & 21,6 & 34,7 \\
\hline & Doações & 0,0 & 36,1 & 17,1 & 16,7 & 0,0 & 0,0 & 6,1 & 12,8 & 26,3 & 0,0 & 28,9 & 11,2 \\
\hline & Outros & 38,0 & 15,2 & 12,8 & 6,6 & 51,2 & 45,4 & 20,5 & 7,8 & 26,8 & 27,6 & 13,1 & 9,4 \\
\hline & Estrutura & 1,1 & 6,2 & 10,6 & 11,6 & 18,7 & 11,8 & 13,2 & 15,9 & 4,1 & 26,1 & 13,5 & 18,3 \\
\hline & Pessoal & 47,1 & 24,7 & 20,1 & 29,0 & 13,6 & 15,1 & 22,5 & 20,9 & 28,0 & 46,3 & 23,0 & 26,4 \\
\hline \multirow{5}{*}{$\begin{array}{l}\text { Oligárquicos/ } \\
\text { Organização } \\
\text { mista }\end{array}$} & Comunicação & 29,0 & 29,3 & 13,7 & 38,0 & 23,6 & 37,3 & 38,7 & 35,1 & 8,3 & 18,3 & 22,4 & 28,9 \\
\hline & Doações & 0,0 & 0,0 & 57,5 & 13,6 & 0,0 & 8,0 & 1,1 & 19,3 & 37,3 & 0,0 & 23,9 & 29,5 \\
\hline & Outros & 60,9 & 28,4 & 8,3 & 7,3 & 51,2 & 19,6 & 27,3 & 9,6 & 11,0 & 19,7 & 18,0 & 8,3 \\
\hline & Estrutura & 1,1 & 7,2 & 4,4 & 11,7 & 13,3 & 10,9 & 14,5 & 13,0 & 12,7 & 17,2 & 19,1 & 13,0 \\
\hline & Pessoal & 9,0 & 35,2 & 16,1 & 29,4 & 11,9 & 24,2 & 18,5 & 23,0 & 30,6 & 44,8 & 16,5 & 20,2 \\
\hline \multirow{5}{*}{$\begin{array}{l}\text { Monocrático/ } \\
\text { Organizados }\end{array}$} & Comunicação & 17,8 & 24,3 & 33,3 & 33,3 & 15,3 & 22,5 & 35,1 & 38,1 & 6,2 & 16,0 & 32,3 & 30,3 \\
\hline & Doações & 0,0 & 37,7 & 14,0 & 11,9 & 0,0 & 0,0 & 0,0 & 17,5 & 2,0 & 0,0 & 5,0 & 11,5 \\
\hline & Outros & 43,5 & 14,8 & 22,7 & 11,5 & 31,5 & 47,4 & 18,4 & 6,0 & 10,9 & 21,2 & 26,5 & 12,3 \\
\hline & Estrutura & 10,2 & 2,9 & 8,4 & 11,9 & 35,5 & 18,4 & 16,7 & 13,8 & 10,7 & 8,0 & 16,6 & 17,4 \\
\hline & Pessoal & 28,5 & 20,3 & 21,6 & 31,4 & 17,7 & 11,6 & 29,8 & 24,6 & 70,3 & 54,8 & 19,7 & 28,5 \\
\hline \multirow{5}{*}{$\begin{array}{l}\text { Pouco } \\
\text { organizados }\end{array}$} & Comunicação & 25,3 & 28,8 & 33,5 & 35,9 & 32,9 & 35,1 & 34,8 & 38,6 & 9,4 & 21,6 & 17,6 & 28,3 \\
\hline & Doações & 2,3 & 6,5 & 13,9 & 13,7 & 2,5 & 3,1 & 9,0 & 18,7 & 9,5 & 5,0 & 34,7 & 10,8 \\
\hline & Outros & 35,9 & 26,1 & 18,2 & 12,4 & 37,9 & 34,7 & 23,8 & 10,0 & 44,1 & 22,0 & 12,8 & 13,5 \\
\hline & Estrutura & 5,2 & 4,2 & 8,4 & 10,1 & 8,6 & 9,5 & 14,0 & 13,9 & 12,1 & 17,1 & 12,6 & 17,2 \\
\hline & Pessoal & 31,4 & 34,4 & 26,1 & 27,9 & 18,1 & 17,5 & 18,4 & 18,8 & 24,9 & 34,3 & 22,3 & 30,2 \\
\hline
\end{tabular}

Fonte: Elaborado pelos autores com base em dados do TSE.

A Tabela 5 apresenta os resultados descritivos dos partidos classificados por Guarnieri. Utilizamos aleatoriamente dados do estado de Minas Gerais para fazer um comparativo explorando os diferentes tipos de gasto entre os candidatos de um mesmo partido, no mesmo estado, procurando notar por meio da observação mais aproximada os efeitos sugeridos por Guarnieri.

Guarnieri classifica os partidos em um contínuo que vai do PT, o partido mais descentralizado, até o PTB, o mais centralizado, conforme a Tabela 5. Comparativamente, de forma geral nota-se que indistintamente todos os candidatos de todos os partidos apresentaram maiores volumes de despesas totais no último quartil. Porém, não há características marcantes que distingam os partidos nas formas como 
seus candidatos empregaram os recursos, apresentando distribuições similares com os gastos concentrando-se, no último quartil, em despesas com "comunicação" e "pessoal".

Tabela 5

Distribuição de despesas por votos em quartis segundo partido - MG

\begin{tabular}{|c|c|c|c|c|c|c|c|c|c|c|}
\hline \multirow{3}{*}{ Despesa } & \multirow{3}{*}{ Partido } & \multicolumn{4}{|c|}{ Votos por quartis } & \multirow{3}{*}{ Partido } & \multicolumn{4}{|c|}{ Votos por quartis } \\
\hline & & $\begin{array}{c}10 \\
\text { quartil } \\
\end{array}$ & $\begin{array}{c}2^{\circ} \\
\text { quartil } \\
\end{array}$ & $\begin{array}{c}3^{\circ} \\
\text { quartil } \\
\end{array}$ & $\begin{array}{c}4^{\circ} \\
\text { quartil } \\
\end{array}$ & & $\begin{array}{c}10 \\
\text { quartil } \\
\end{array}$ & $\begin{array}{c}20 \\
\text { quartil } \\
\end{array}$ & $\begin{array}{c}3^{\circ} \\
\text { quartil } \\
\end{array}$ & $\begin{array}{c}4^{\circ} \\
\text { quartil } \\
\end{array}$ \\
\hline & & Mean & Mean & Mean & Mean & & Mean & Mean & Mean & Mean \\
\hline Comunicação & \multirow{6}{*}{ PP } & 0 & 8,4 & 0,0 & 22,7 & \multirow{6}{*}{ PTB } & 17,2 & 43,8 & 11,6 & 53,6 \\
\hline Doações & & 0 & 0,0 & 0,0 & 4,4 & & 0,0 & 0,4 & 8,1 & 0,9 \\
\hline Estrutura & & 96 & 0,0 & 0,0 & 15,9 & & 18,8 & 5,1 & 6,2 & 9,6 \\
\hline Outros & & 0 & 91,6 & 0,0 & 24,5 & & 23,7 & 24,8 & 3,8 & 15,4 \\
\hline Pessoal & & 4 & 0,0 & 0,0 & 32,4 & & 40,4 & 25,9 & 70,2 & 20,5 \\
\hline Total & & 5.000 & 6.518 & 0 & 1.469 .597 & & 4.822 & 13.167 & 94.243 & 269.079 \\
\hline Comunicação & \multirow{6}{*}{ DEM } & 0,0 & 45,4 & 0,0 & 34,6 & \multirow{6}{*}{ PSDB } & 11,0 & 19,9 & 0,0 & 33,7 \\
\hline Doações & & 0,0 & 0,0 & 0,0 & 1,7 & & 0,0 & 0,0 & 0,0 & 7,0 \\
\hline Estrutura & & 0,0 & 7,9 & 0,0 & 23,4 & & 0,0 & 34,6 & 0,0 & 16,9 \\
\hline Outros & & 100,0 & 27,5 & 0,0 & 3,7 & & 89,0 & 45,5 & 100,0 & 7,3 \\
\hline Pessoal & & 0,0 & 19,2 & 0,0 & 36,6 & & 0,0 & 0,0 & 0,0 & 35,1 \\
\hline Total & & 2.261 & 7.318 & 0 & 1.393 .547 & & 3.427 & 3.426 & 2.504 & 1.868 .291 \\
\hline Comunicação & \multirow{6}{*}{ PMDB } & 10,3 & 14,4 & 46,4 & 27,4 & \multirow{6}{*}{ PT } & 0,0 & 37,2 & 44,0 & 28,9 \\
\hline Doações & & 0,0 & 0,0 & 0,0 & 17,1 & & 0,0 & 0,0 & 0,6 & 6,6 \\
\hline Estrutura & & 6,2 & 25,3 & 25,0 & 17,7 & & 0,0 & 5,3 & 15,6 & 18,7 \\
\hline Outros & & 83,5 & 9,9 & 20,7 & 7,0 & & 0,0 & 52,3 & 17,5 & 8,5 \\
\hline Pessoal & & 0,0 & 50,4 & 7,9 & 30,8 & & 0,0 & 5,2 & 22,3 & 37,3 \\
\hline Total & & 1.821 & 4.723 & 26.233 & 1.551 .829 & & 0 & 7.026 & 57.629 & 1.190 .270 \\
\hline
\end{tabular}

Fonte: Elaborada pelos autores com base em dados do TSE.

A heterogeneidade nos padrões de gastos entre as unidades da federação também ficou bastante evidente, conforme mostra a Tabela 6: 
Tabela 6

Distribuição despesas segundo unidade da federação

\begin{tabular}{|c|c|c|c|c|c|c|c|}
\hline UF & $\begin{array}{c}\text { Comunicação } \\
\text { e } \\
\text { publicidade } \\
(\%)\end{array}$ & $\begin{array}{c}\text { Estrutura } \\
(\%)\end{array}$ & $\begin{array}{c}\text { Pessoal } \\
(\%)\end{array}$ & $\begin{array}{c}\text { Doações a } \\
\text { outros } \\
\text { candidatos } \\
\text { e comitês } \\
(\%)\end{array}$ & $\begin{array}{c}\text { Despesas } \\
\text { em } \\
\text { outros } \\
(\%)\end{array}$ & Total & $\begin{array}{c}\text { Total } \\
\text { despesas } \\
(\%)\end{array}$ \\
\hline SP & 37 & 8 & 29 & 5 & 21 & $284.817 .835,67$ & 17,1 \\
\hline MG & 36 & 15 & 37 & 2 & 9 & $190.287 .196,24$ & 11,5 \\
\hline PR & 32 & 14 & 19 & 7 & 28 & $115.477 .831,07$ & 7,0 \\
\hline RJ & 50 & 11 & 20 & 7 & 12 & $109.559 .250,52$ & 6,6 \\
\hline GO & 29 & 13 & 34 & 8 & 17 & $104.323 .628,18$ & 6,3 \\
\hline BA & 45 & 17 & 17 & 9 & 11 & $82.632 .197,68$ & 5,0 \\
\hline RS & 51 & 12 & 22 & 6 & 9 & $71.429 .816,36$ & 4,3 \\
\hline CE & 17 & 8 & 7 & 1 & 67 & $65.323 .085,28$ & 3,9 \\
\hline MT & 24 & 15 & 49 & 5 & 7 & $62.824 .898,59$ & 3,8 \\
\hline $\mathrm{PE}$ & 62 & 15 & 11 & 7 & 4 & $58.716 .820,59$ & 3,5 \\
\hline$A L$ & 41 & 20 & 27 & 4 & 9 & $51.976 .857,53$ & 3,1 \\
\hline MA & 44 & 20 & 21 & 1 & 14 & $43.957 .006,00$ & 2,6 \\
\hline MS & 18 & 12 & 29 & 34 & 8 & $41.355 .900,00$ & 2,5 \\
\hline PB & 68 & 13 & 9 & 1 & 8 & $38.724 .912,28$ & 2,3 \\
\hline AM & 30 & 21 & 33 & 7 & 9 & $36.913 .063,09$ & 2,2 \\
\hline SC & 37 & 8 & 16 & 7 & 31 & $36.455 .559,07$ & 2,2 \\
\hline ES & 50 & 13 & 23 & 6 & 7 & $34.931 .720,77$ & 2,1 \\
\hline PA & 35 & 17 & 7 & 10 & 31 & $33.569 .525,82$ & 2,0 \\
\hline $\mathrm{RO}$ & 25 & 16 & 26 & 3 & 30 & $32.609 .538,18$ & 2,0 \\
\hline $\mathrm{PI}$ & 37 & 18 & 22 & 1 & 25 & $28.373 .438,41$ & 1,7 \\
\hline TO & 17 & 14 & 16 & 5 & 48 & $27.567 .498,27$ & 1,7 \\
\hline DF & 51 & 11 & 19 & 13 & 7 & $26.483 .812,67$ & 1,6 \\
\hline RR & 19 & 19 & 47 & 6 & 9 & $25.759 .843,92$ & 1,6 \\
\hline RN & 37 & 22 & 24 & 2 & 16 & $24.144 .698,65$ & 1,5 \\
\hline SE & 45 & 19 & 11 & 0 & 25 & $16.555 .037,94$ & 1,0 \\
\hline AP & 28 & 12 & 5 & 2 & 53 & $9.291 .216,48$ & 0,6 \\
\hline$A C$ & 27 & 24 & 8 & 16 & 25 & $6.873 .343,86$ & 0,4 \\
\hline Total & 37 & 15 & 22 & 6 & 20 & $1.660 .935 .533,12$ & 100,0 \\
\hline DP & 0,13 & 0,04 & 0,11 & 0,07 & 0,15 & $58.637 .724,58$ & 0,04 \\
\hline $\mathrm{CV}$ & 2,81 & 3,55 & 1,93 & 0,99 & 1,3 & 28,33 & 28,33 \\
\hline
\end{tabular}

Fonte: Elaborada pelos autores com base em dados do TSE. 
Os estados que apresentaram os maiores gastos em "comunicação e publicidade" foram PB (68\%) e PE (62\%). Além destes, também ficam acima dos 50\%: RS, DF, RJ e ES. Os menores percentuais de gastos em publicidade foram para TO, CE, MS e RR, todos abaixo de $20 \%$ de gastos em "comunicação".

Os gastos com "estrutura" tiveram nos estados AC, RN, AM e MA os maiores percentuais, todos acima de $20 \%$. E as despesas com "pessoal" são maiores no MT (49\%), RR (47\%) e MG (37\%).

Ao observarmos o coeficiente de variação (CV) entre as despesas observadas na Tabela 2, verificamos novamente que os gastos de "comunicação e publicidade" e de "estrutura" foram os que mais variaram, com os respectivos valores de 2,81 e 3,55. Esses dados, combinados com a descrição das porcentagens nos estados, demonstram como a particularidade de cada distrito influencia muito em possíveis explicações sobre padrões de disputas e profissionalização das campanhas.

\section{Apresentação das variáveis}

Nesta seção apresentamos as variáveis derivadas da classificação das despesas já detalhada no texto ${ }^{7}$. Para tornarmos viável a análise das despesas na regressão logística, realizamos a categorização de cada tipo de gasto em quartis, seguindo a divisão natural dos valores apresentados pelos candidatos em cinco níveis.

$\mathrm{Na}$ Tabela 7 apresentamos os gastos ponderados por unidade da federação. Isso quer dizer que calculamos o quanto representa no estado o gasto do candidato em relação aos seus concorrentes no mesmo tipo de despesa.

Nessa tabela vemos que apenas $1 \%$ dos deputados eleitos não apresentaram qualquer despesa com "pessoal". Além disso, somente $2 \%$ dos eleitos não tiveram nenhuma despesa categorizada como "outros". Esses valores diminuíram ainda mais quando consideramos os gastos com "comunicação" e "estrutura". Em ambos os casos, apenas o percentual de eleitos que não apresentou gastos nessas áreas não atinge $1 \%$ dos casos. Comparativamente, vemos que quase todos os candidatos eleitos gastaram em "comunicação" e "estrutura".

\footnotetext{
7 Aqui, mensuramos a correlação entre variáveis ordinais e nominais, e utilizamos o coeficiente de contingência e o V de Cramer (Barbetta, 2004). Para mensurar a magnitude das correlações encontradas adotou-se Davis (apud Barbetta, 2004), para quem a correlação compreendida entre 0 e 0,09 é considerada associação desprezível; de 0,10 a 0,29 , associação baixa; de 0,30 a 0,49 , associação moderada; de 0,50 a 0,69, associação substancial e de 0,70 ou mais, associação forte.
} 
Tabela 7

Despesas ponderadas por UF

\begin{tabular}{|c|c|c|c|c|c|c|c|c|}
\hline Variável & Categoria & $\begin{array}{c}\text { Não } \\
\text { eleito }\end{array}$ & $\%$ & Eleito & $\%$ & Total & $\begin{array}{l}\text { Symmetric } \\
\text { Measures }\end{array}$ & Value \\
\hline \multirow{6}{*}{$\begin{array}{l}\text { Despesa } \\
\text { pessoal (UF) }\end{array}$} & $\begin{array}{c}\text { Sem } \\
\text { despesa }\end{array}$ & 1850 & 0,99 & 22 & 0,01 & 1872 & Phi & 0,596 \\
\hline & $\begin{array}{l}\text { Menores } \\
\text { despesas }\end{array}$ & 625 & 0,97 & 17 & 0,03 & 642 & Cramer's V & 0,596 \\
\hline & $\begin{array}{c}\text { Despesas } \\
\text { médias } \\
\text { baixas }\end{array}$ & 465 & 0,94 & 28 & 0,06 & 493 & $\begin{array}{c}\text { Contingency } \\
\text { Coefficient }\end{array}$ & 0,512 \\
\hline & $\begin{array}{l}\text { Despesas } \\
\text { médias } \\
\text { altas }\end{array}$ & 391 & 0,73 & 146 & 0,27 & 537 & $\begin{array}{c}\text { Pearson } \\
\text { Chi-Square }\end{array}$ & $1432,967 a$ \\
\hline & $\begin{array}{c}\text { Maiores } \\
\text { despesas }\end{array}$ & 194 & 0,39 & 300 & 0,61 & 494 & Sig & 0 \\
\hline & Total & 3525 & 0,87 & 513 & 0,13 & 4038 & & \\
\hline \multirow{6}{*}{$\begin{array}{l}\text { Despesa } \\
\text { outros (UF) }\end{array}$} & $\begin{array}{c}\text { Sem } \\
\text { despesa }\end{array}$ & 385 & 0,98 & 9 & 0,02 & 394 & Phi & 0,503 \\
\hline & $\begin{array}{l}\text { Menores } \\
\text { despesas }\end{array}$ & 1196 & 1,00 & 6 & 0,00 & 1202 & Cramer's V & 0,503 \\
\hline & $\begin{array}{c}\text { Despesas } \\
\text { médias } \\
\text { baixas }\end{array}$ & 683 & 0,98 & 16 & 0,02 & 699 & $\begin{array}{c}\text { Contingency } \\
\text { Coefficient }\end{array}$ & 0,449 \\
\hline & $\begin{array}{l}\text { Despesas } \\
\text { médias } \\
\text { altas }\end{array}$ & 781 & 0,88 & 106 & 0,12 & 887 & $\begin{array}{c}\text { Pearson } \\
\text { Chi-Square }\end{array}$ & $1432,967 a$ \\
\hline & $\begin{array}{l}\text { Maiores } \\
\text { despesas }\end{array}$ & 480 & 0,56 & 376 & 0,44 & 856 & Sig & 0 \\
\hline & Total & 3525 & 0,87 & 513 & 0,13 & 4038 & & \\
\hline \multirow{6}{*}{$\begin{array}{l}\text { Despesa } \\
\text { estrutura } \\
\text { (UF) }\end{array}$} & $\begin{array}{c}\text { Sem } \\
\text { despesa }\end{array}$ & 1457 & 1,00 & 2 & 0,00 & 1459 & Phi & 0,633 \\
\hline & $\begin{array}{l}\text { Menores } \\
\text { despesas }\end{array}$ & 940 & 0,99 & 14 & 0,01 & 954 & Cramer's V & 0,633 \\
\hline & $\begin{array}{c}\text { Despesas } \\
\text { médias } \\
\text { baixas }\end{array}$ & 369 & 0,97 & 12 & 0,03 & 381 & $\begin{array}{c}\text { Contingency } \\
\text { Coefficient }\end{array}$ & 0,535 \\
\hline & $\begin{array}{c}\text { Despesas } \\
\text { médias } \\
\text { altas }\end{array}$ & 524 & 0,81 & 121 & 0,19 & 645 & $\begin{array}{c}\text { Pearson } \\
\text { Chi-Square }\end{array}$ & $1616,316 a$ \\
\hline & $\begin{array}{c}\text { Maiores } \\
\text { Despesas }\end{array}$ & 235 & 0,39 & 364 & 0,61 & 599 & Sig & 0 \\
\hline & Total & 3525 & 0,87 & 513 & 0,13 & 4038 & & \\
\hline
\end{tabular}




\begin{tabular}{|c|c|c|c|c|c|c|c|c|}
\hline Variável & Categoria & $\begin{array}{c}\text { Não } \\
\text { eleito }\end{array}$ & $\%$ & Eleito & $\%$ & Total & $\begin{array}{l}\text { Symmetric } \\
\text { Measures }\end{array}$ & Value \\
\hline \multirow{6}{*}{$\begin{array}{l}\text { Despesa } \\
\text { doações } \\
\text { (UF) }\end{array}$} & $\begin{array}{c}\text { Sem } \\
\text { despesa }\end{array}$ & 3248 & 0,92 & 296 & 0,08 & 3544 & Phi & 0,414 \\
\hline & $\begin{array}{l}\text { Menores } \\
\text { Despesas }\end{array}$ & 118 & 0,89 & 15 & 0,11 & 133 & Cramer's V & 0,414 \\
\hline & $\begin{array}{c}\text { Despesas } \\
\text { Médias } \\
\text { Baixas } \\
\end{array}$ & 72 & 0,55 & 59 & 0,45 & 131 & $\begin{array}{c}\text { Contingency } \\
\text { Coefficient }\end{array}$ & 0,383 \\
\hline & $\begin{array}{c}\text { Despesas } \\
\text { médias } \\
\text { altas }\end{array}$ & 52 & 0,39 & 81 & 0,61 & 133 & $\begin{array}{c}\text { Pearson } \\
\text { Chi-Square }\end{array}$ & $692,254 a$ \\
\hline & $\begin{array}{c}\text { Maiores } \\
\text { despesas }\end{array}$ & 35 & 0,36 & 62 & 0,64 & 97 & Sig & 0 \\
\hline & Total & 3525 & 0,87 & 513 & 0,13 & 4038 & & \\
\hline \multirow{6}{*}{$\begin{array}{l}\text { Despesa } \\
\text { comunicação } \\
\text { (UF) }\end{array}$} & $\begin{array}{c}\text { Sem } \\
\text { despesa }\end{array}$ & 1097 & 1,00 & 2 & 0,00 & 1099 & Phi & 0,651 \\
\hline & $\begin{array}{l}\text { Menores } \\
\text { despesas }\end{array}$ & 1072 & 0,99 & 8 & 0,01 & 1080 & Cramer's V & 0,651 \\
\hline & $\begin{array}{c}\text { Despesas } \\
\text { médias } \\
\text { baixas }\end{array}$ & 454 & 0,99 & 3 & 0,01 & 457 & $\begin{array}{c}\text { Contingency } \\
\text { Coefficient }\end{array}$ & 0,545 \\
\hline & $\begin{array}{c}\text { Despesas } \\
\text { médias } \\
\text { altas } \\
\end{array}$ & 625 & 0,87 & 92 & 0,13 & 717 & $\begin{array}{c}\text { Pearson } \\
\text { Chi-Square }\end{array}$ & $1710,598 a$ \\
\hline & $\begin{array}{c}\text { Maiores } \\
\text { despesas }\end{array}$ & 277 & 0,40 & 408 & 0,60 & 685 & Sig & 0 \\
\hline & Total & 3525 & 0,87 & 513 & 0,13 & 4038 & & \\
\hline \multirow{5}{*}{$\begin{array}{l}\text { Despesa } \\
\text { total (UF) }\end{array}$} & $\begin{array}{l}\text { Menores } \\
\text { despesas }\end{array}$ & 1612 & 1,00 & 3 & 0,00 & 1615 & Phi & 0,62 \\
\hline & $\begin{array}{c}\text { Despesas } \\
\text { médias } \\
\text { baixas }\end{array}$ & 594 & 1,00 & 1 & 0,00 & 595 & Cramer's V & 0,62 \\
\hline & $\begin{array}{c}\text { Despesas } \\
\text { médias } \\
\text { altas } \\
\end{array}$ & 848 & 0,96 & 38 & 0,04 & 886 & $\begin{array}{l}\text { Contingency } \\
\text { Coefficient }\end{array}$ & 0,527 \\
\hline & $\begin{array}{c}\text { Maiores } \\
\text { despesas }\end{array}$ & 471 & 0,50 & 471 & 0,50 & 942 & $\begin{array}{c}\text { Pearson } \\
\text { Chi-Square }\end{array}$ & $1550,578 a$ \\
\hline & Total & 3525 & 0,87 & 513 & 0,13 & 4038 & Sig & 0 \\
\hline
\end{tabular}

Fonte: Elaborada pelos autores com base em dados do TSE.

Quanto ao volume total de dinheiro gasto na eleição, verificamos que, dentre os candidatos com as maiores despesas, exatamente metade deles (471) foi eleita. Ou seja, $90 \%$ dos 513 deputados tiveram as maiores despesas totais de seus respectivos estados.

Ressaltamos que, em todas as variáveis, o teste chi-quadrado mostrou que as distribuições não foram independentes entre os gastos e o resultado eleitoral. Ou seja, a probabilidade da distribuição ao acaso entre a forma como os candidatos gastaram seus recursos e o sucesso eleitoral foi nula. 
Testamos os graus de associação entre os diferentes tipos de despesas em relação à votação obtida pelos candidatos agregada em quartis, de forma a oferecer uma visão alternativa à visão dicotômica resumida ao resultado eleitoral (eleito/não eleito). Todas as despesas apresentam associação com votos. Porém a força dessa associação, conforme a hipótese deste artigo, varia conforme o tipo de despesa. Em distritos eleitorais de alta magnitude, a associação é forte para despesas com "comunicação" e "estrutura" e substancial para os demais tipos de despesa, conforme os escores apresentados na Tabela 8:

Tabela 8

Correlação de votos por quartis segundo o tipo despesa em UF de alta magnitude (SP, MG, RJ, BA)

\begin{tabular}{|l|c|c|c|c|}
\hline Tipo despesa & Pearson & Spearman & $\begin{array}{c}\text { Sign } \\
\mathbf{( 9 5 \% )}\end{array}$ & $\begin{array}{c}\text { Chi-Square } \\
\text { tests }\end{array}$ \\
\hline Comunicação &, 777 &, 798 & 0,000 & 1349,719 \\
\hline Doações &, 594 &, 623 & 0,000 & 103,924 \\
\hline Estrutura &, 703 &, 735 & 0,000 & 859,779 \\
\hline Outros &, 678 &, 679 & 0,000 & 1320,611 \\
\hline Pessoal &, 684 &, 713 & 0,000 & 669,697 \\
\hline Total &, 777 &, 778 & 0,000 & 2051,973 \\
\hline
\end{tabular}

Fonte: Elaborada pelos autores com base em dados do TSE.

Em distritos eleitorais de média magnitude, a associação é forte para despesas com "comunicação", "estrutura" e também com "pessoal", sendo substancial para os demais tipos de despesas.

Tabela 9

Correlação de votos por quartis segundo o tipo de despesa em UF de média magnitude (CE, GO, MA, PA, PE, PR, RS, SC)

\begin{tabular}{|l|c|c|c|c|}
\hline Tipo despesa & Pearson & Spearman & $\begin{array}{c}\text { Sign } \\
\mathbf{( 9 5 \% )}\end{array}$ & $\begin{array}{c}\text { Chi-Square } \\
\text { tests }\end{array}$ \\
\hline Comunicação &, 824 &, 839 & 0,000 & 889,818 \\
\hline Doações &, 567 &, 579 & 0,000 & 79,229 \\
\hline Estrutura &, 740 &, 769 & 0,000 & 535,141 \\
\hline Outros &, 674 &, 678 & 0,000 & 527,885 \\
\hline Pessoal &, 718 &, 738 & 0,000 & 410,495 \\
\hline Total &, 801 &, 801 & 0,000 & 1126,920 \\
\hline
\end{tabular}

Fonte: Elaborada pelos autores com base em dados do TSE. 
Já em distritos eleitorais de baixa magnitude são as despesas com "comunicação" que possuem o mais forte grau de associação. Para todos os demais tipos de despesas a associação é substancial.

Tabela 10

Correlação de votos por quartis segundo o tipo de despesa em UF de baixa magnitude (AC, AL, AM, AP, ES, DF, MS, MT, PB, PI, RN, RO, RR, SE, TO)

\begin{tabular}{|l|c|c|c|c|}
\hline Tipo despesa & Pearson & Spearman & $\begin{array}{c}\text { Sign } \\
\mathbf{( 9 5 \% )}\end{array}$ & $\begin{array}{c}\text { Chi-Square } \\
\text { tests }\end{array}$ \\
\hline Comunicação &, 784 &, 799 & 0,000 & 518,075 \\
\hline Doações &, 547 &, 534 & 0,000 & 51,785 \\
\hline Estrutura &, 670 &, 691 & 0,000 & 358,370 \\
\hline Outros &, 636 &, 638 & 0,000 & 381,664 \\
\hline Pessoal &, 546 &, 578 & 0,000 & 188,383 \\
\hline Total &, 757 &, 757 & 0,000 & 677,970 \\
\hline
\end{tabular}

Fonte: Elaborada pelos autores com base em dados do TSE.

Na Tabela 11 examinamos o segundo grupo de variáveis derivadas das despesas. Nesse caso, calculamos os tipos de gastos pelo total de despesas do próprio candidato. Em seguida, também categorizamos essas porcentagens em quartis, incluindo os candidatos que não tiveram gastos em determinada rubrica como "sem despesa":

Tabela 11

Despesas ponderadas por candidato

\begin{tabular}{|c|c|c|c|c|c|c|c|c|}
\hline Variável & Categoria & \begin{tabular}{|c|} 
Não \\
eleito
\end{tabular} & $\%$ & Eleito & $\%$ & Total & Symmetric Measures & Value \\
\hline \multirow{6}{*}{$\begin{array}{l}\text { Despesa } \\
\text { comunicação } \\
\text { (cand.) }\end{array}$} & Sem despesa & 1097 & 1,00 & 2 & 0,00 & 1099 & Phi & 0,284 \\
\hline & $\begin{array}{l}\text { Menores } \\
\text { despesas }\end{array}$ & 663 & 0,90 & 70 & 0,10 & 733 & Cramer's V & 0,284 \\
\hline & $\begin{array}{c}\text { Despesas } \\
\text { médias } \\
\text { baixas }\end{array}$ & 583 & 0,79 & 158 & 0,21 & 741 & Contingency Coefficient & 0,274 \\
\hline & $\begin{array}{c}\text { Despesas } \\
\text { médias altas }\end{array}$ & 540 & 0,74 & 189 & 0,26 & 729 & Pearson Chi-Square & $326,505 a$ \\
\hline & $\begin{array}{c}\text { Maiores } \\
\text { despesas }\end{array}$ & 642 & 0,87 & 94 & 0,13 & 736 & Sig & 0 \\
\hline & Total & 3525 & 0,87 & 513 & 0,13 & 4038 & & \\
\hline \multirow{6}{*}{$\begin{array}{l}\text { Despesa } \\
\text { doações } \\
\text { (cand.) }\end{array}$} & Sem despesa & 3248 & 0,92 & 296 & 0,08 & 3544 & Phi & 0,353 \\
\hline & $\begin{array}{l}\text { Menores } \\
\text { despesas }\end{array}$ & 78 & 0,62 & 47 & 0,38 & 125 & Cramer's V & 0,353 \\
\hline & $\begin{array}{c}\text { Despesas } \\
\text { médias } \\
\text { baixas }\end{array}$ & 64 & 0,52 & 60 & 0,48 & 124 & Contingency Coefficient & 0,332 \\
\hline & $\begin{array}{c}\text { Despesas } \\
\text { médias altas }\end{array}$ & 67 & 0,56 & 53 & 0,44 & 120 & Pearson Chi-Square & $501,824 a$ \\
\hline & $\begin{array}{l}\text { Maiores } \\
\text { despesas }\end{array}$ & 68 & 0,54 & 57 & 0,46 & 125 & Sig & 0 \\
\hline & Total & 3525 & 0,87 & 513 & 0,13 & 4038 & & \\
\hline
\end{tabular}


JEISON GIOVANI HEILER; JOÃO PAULO SARAIVA LEÃO VIANA; RODRIGO DOLANDELI DOS SANTOS

\begin{tabular}{|c|c|c|c|c|c|c|c|c|}
\hline Variável & Categoria & \begin{tabular}{|c|} 
Não \\
eleito
\end{tabular} & $\%$ & Eleito & $\%$ & Total & Symmetric Measures & Value \\
\hline \multirow{6}{*}{$\begin{array}{l}\text { Despesa } \\
\text { estrutura } \\
\text { (cand.) }\end{array}$} & Sem despesa & 1457 & 1,00 & 2 & 0,00 & 1459 & Phi & 0,351 \\
\hline & $\begin{array}{l}\text { Menores } \\
\text { despesas }\end{array}$ & 601 & 0,94 & 40 & 0,06 & 641 & Cramer's V & 0,351 \\
\hline & $\begin{array}{c}\text { Despesas } \\
\text { médias } \\
\text { baixas }\end{array}$ & 525 & 0,81 & 126 & 0,19 & 651 & Contingency Coefficient & 0,331 \\
\hline & $\begin{array}{c}\text { Despesas } \\
\text { médias altas }\end{array}$ & 448 & 0,70 & 189 & 0,30 & 637 & Pearson Chi-Square & $498,000 a$ \\
\hline & $\begin{array}{c}\text { Maiores } \\
\text { despesas }\end{array}$ & 494 & 0,76 & 156 & 0,24 & 650 & Sig & 0 \\
\hline & Total & 3525 & 0,87 & 513 & 0,13 & 4038 & & \\
\hline \multirow{6}{*}{$\begin{array}{l}\text { Despesa } \\
\text { outros } \\
\text { (cand.) }\end{array}$} & Sem despesa & 385 & 0,98 & 9 & 0,02 & 394 & Phi & 0,399 \\
\hline & $\begin{array}{l}\text { Menores } \\
\text { despesas }\end{array}$ & 588 & 0,65 & 310 & 0,35 & 898 & Cramer's V & 0,399 \\
\hline & $\begin{array}{c}\text { Despesas } \\
\text { médias } \\
\text { baixas }\end{array}$ & 754 & 0,82 & 160 & 0,18 & 914 & Contingency Coefficient & 0,37 \\
\hline & $\begin{array}{c}\text { Despesas } \\
\text { médias altas }\end{array}$ & 888 & 0,96 & 33 & 0,04 & 921 & Pearson Chi-Square & $642,365 a$ \\
\hline & $\begin{array}{l}\text { Maiores } \\
\text { despesas }\end{array}$ & 910 & 1,00 & 1 & 0,00 & 911 & Sig & 0 \\
\hline & Total & 3525 & 0,87 & 513 & 0,13 & 4038 & & \\
\hline \multirow{6}{*}{$\begin{array}{l}\text { Despesa } \\
\text { pessoal } \\
\text { (cand.) }\end{array}$} & Sem despesa & 1850 & 0,99 & 22 & 0,01 & 1872 & Phi & 0,337 \\
\hline & $\begin{array}{l}\text { Menores } \\
\text { despesas }\end{array}$ & 430 & 0,80 & 106 & 0,20 & 536 & Cramer's V & 0,337 \\
\hline & $\begin{array}{c}\text { Despesas } \\
\text { médias } \\
\text { baixas }\end{array}$ & 385 & 0,71 & 155 & 0,29 & 540 & Contingency Coefficient & 0,319 \\
\hline & $\begin{array}{c}\text { Despesas } \\
\text { médias altas }\end{array}$ & 408 & 0,75 & 137 & 0,25 & 545 & Pearson Chi-Square & $458,482 a$ \\
\hline & $\begin{array}{c}\text { Maiores } \\
\text { despesas }\end{array}$ & 452 & 0,83 & 93 & 0,17 & 545 & Sig & 0 \\
\hline & Total & 3525 & 0,87 & 513 & 0,13 & 4038 & & \\
\hline \multirow{5}{*}{$\begin{array}{l}\text { Padrão de } \\
\text { gastos } \\
\text { (cand.) }\end{array}$} & $\begin{array}{c}\text { Recursos } \\
\text { concentrados }\end{array}$ & 2066 & 0,87 & 316 & 0,13 & 2382 & Phi & 0,03 \\
\hline & $\begin{array}{l}\text { Recursos } \\
\text { divididos }\end{array}$ & 1229 & 0,88 & 173 & 0,12 & 1402 & Cramer's V & 0,03 \\
\hline & $\begin{array}{c}\text { Recursos } \\
\text { pulverizados }\end{array}$ & 228 & 0,90 & 24 & 0,10 & 252 & Contingency Coefficient & 0,03 \\
\hline & & & & & & & Pearson Chi-Square & $3,711 a$ \\
\hline & Total & 3525 & 0,87 & 513 & 0,13 & 4038 & Sig & 0,447 \\
\hline
\end{tabular}

Fonte: Elaborada pelos autores com base em dados do TSE.

Ao analisar os gastos ponderados por candidato, verificamos uma diferença drástica: a porcentagem de candidatos não eleitos foi muito maior em todas as categorias (menores despesas, despesas médias baixas, despesas médias altas e maiores despesas) em comparação à dos deputados eleitos. Portanto, a princípio, inferimos que para o candidato não basta destinar seus recursos em determinados tipos de gasto sem que haja um volume de recursos compatível com o nível de disputa do distrito. 
Na Tabela 11 também apresentamos a variável "padrão de gastos", que identifica a forma como as despesas foram empreendidas pelos candidatos. Assim, os "recursos concentrados" retratam os candidatos cujos gastos se enquadraram nos quartis "despesas médias altas" ou "maiores despesas" em apenas um tipo de despesa. Em "recursos divididos", os candidatos tiveram duas rubricas enquadradas nos quartis "despesas médias altas" ou "maiores despesas". Por último, "recursos pulverizados" mostram os candidatos que tiveram três ou quatro despesas ao mesmo tempo nos quartis "despesas médias altas" ou "maiores despesas".

Essa variável mostrou claramente que os candidatos concentraram seus recursos em um tipo de gasto apenas. Porém, a estatística chi-quadrado não obteve significância, atestando que a distribuição dessa variável e a do sucesso eleitoral foram independentes. Para todas as outras variáveis dessa tabela os valores foram estatisticamente significantes.

Nas próximas tabelas descreveremos a distribuição percentual das variáveis políticas e socioeconômicas que serão testadas na análise multivariada.

$\mathrm{Na}$ Tabela 12 apresentamos as variáveis políticas que complementaram os testes realizados nos testes de regressão logística. Buscamos testar determinantes já exaustivamente debatidos na literatura sobre partidos, eleições e financiamento de campanha.

Os resultados encontrados com respeito à variável "ideologia" dos partidos nos indicam que as maiores taxas de sucesso foram referentes aos candidatos de partidos classificados como centro-direita (24\%) e direita (21\%). Esses partidos juntos somaram 282 deputados, significando $55 \%$ da Câmara dos deputados ${ }^{8}$ e ratificando a configuração ideológica dessa casa parlamentar. Fato que também guarda relação com os padrões de financiamento de campanha9.

A variável "força política" mostra a já consagrada constatação da literatura do impacto dos incumbents nas eleições. Enquanto para os desafiantes a taxa de sucesso eleitoral foi apenas de $7 \%$, a dos incumbents foi de $75 \%{ }^{10}$.

\footnotetext{
${ }^{8}$ Classificação própria elaborada pelos autores inspirada a partir de Power e Zucco (2012): direita (DEM; PP; PR; PTB); centro-direita (PMDB e PSDB); centro (PPS e PV); centro-esquerda (PDT; PSB; PT); esquerda (PCdoB e PSOL).

9 Para ilustrar a primeira abordagem, como afirma Mancuso (2015), Samuels (apud Mancuso, 2015) constatou, nas eleições de 1998 e 2002 para a Câmara dos Deputados, que o perfil ideológico influenciava nas doações a partidos de esquerda, que recebiam menos valores em geral, e também menos contribuições de pessoas jurídicas. Speck (apud Mancuso, 2015), por sua vez, tendo como foco as eleições de 2010 à Câmara dos Deputados, notou que as doações de empresas foram maiores do que as de pessoas físicas para partidos de centro e de direita, e menor para as legendas situadas à esquerda do espectro ideológico. Além disso, o autor observou o aumento das doações empresariais a partidos de direita, entre as maiores faixas de doação.

$10 \mathrm{Em}$ que pese a relevância do fator incumbency, este foi analisado por Marcelino (2010), Lemos, Marcelino e Pederiva (apud Mancuso, 2015) e Mancuso (2015). No geral, os autores perceberam que os incumbents têm receitas e despesas médias bem superiores aos desafiantes (Mancuso, 2015, p. 22).
} 
Tabela 12

Descrição das variáveis políticas

\begin{tabular}{|c|c|c|c|c|c|c|c|c|}
\hline Variável & Categoria & $\begin{array}{c}\text { Não } \\
\text { eleito }\end{array}$ & $\%$ & Eleito & $\%$ & Total & \begin{tabular}{|c|} 
Symmetric \\
Measures
\end{tabular} & Value \\
\hline \multirow{7}{*}{ Ideologia } & Centro & 390 & 0,94 & 25 & 0,06 & 415 & Phi & 0,256 \\
\hline & Centro-direita & 410 & 0,76 & 132 & 0,24 & 542 & Cramer's V & 0,256 \\
\hline & Centro-esquerda & 643 & 0,81 & 148 & 0,19 & 791 & $\begin{array}{c}\text { Contingency } \\
\text { Coefficient }\end{array}$ & 0,248 \\
\hline & Direita & 579 & 0,79 & 150 & 0,21 & 729 & $\begin{array}{c}\text { Pearson } \\
\text { Chi-Square } \\
\end{array}$ & 265,340 \\
\hline & Esquerda & 267 & 0,94 & 18 & 0,06 & 285 & Sig & 0 \\
\hline & Não classificado & 1236 & 0,97 & 40 & 0,03 & 1276 & & \\
\hline & Total & 3525 & 0,87 & 513 & 0,13 & 4038 & & \\
\hline \multirow{6}{*}{$\begin{array}{l}\text { Posição } \\
\text { do } \\
\text { partido }\end{array}$} & Governo & 1340 & 0,83 & 279 & 0,17 & 1619 & Phi & 0,113 \\
\hline & Independente & 199 & 0,93 & 14 & 0,07 & 213 & Cramer's V & 0,113 \\
\hline & Oposição & 1986 & 0,90 & 220 & 0,10 & 2206 & $\begin{array}{c}\text { Contingency } \\
\text { Coefficient }\end{array}$ & 0,113 \\
\hline & & & & & & & $\begin{array}{c}\text { Pearson } \\
\text { Chi-Square } \\
\end{array}$ & $52,000 a$ \\
\hline & & & & & & & Sig & 0 \\
\hline & Total & 3525 & 0,87 & 513 & 0,13 & 4038 & & \\
\hline \multirow{6}{*}{$\begin{array}{l}\text { Força } \\
\text { política }\end{array}$} & Desafiante & 3436 & 0,93 & 245 & 0,07 & 3681 & Phi & 0,583 \\
\hline & Incumbent & 89 & 0,25 & 268 & 0,75 & 357 & Cramer's V & 0,583 \\
\hline & & & & & & & \begin{tabular}{|c} 
Contingency \\
Coefficient
\end{tabular} & 0,504 \\
\hline & & & & & & & $\begin{array}{c}\text { Pearson } \\
\text { Chi-Square } \\
\end{array}$ & $1373,462 a$ \\
\hline & & & & & & & Sig & 0 \\
\hline & Total & 3525 & 0,87 & 513 & 0,13 & 4038 & & \\
\hline \multirow{5}{*}{$\begin{array}{l}\text { Força do } \\
\text { partido }\end{array}$} & Poliárquicos/Organizados & 446 & 73,1 & 164 & 0,26 & 610 & Phi & 0,232 \\
\hline & Oligárquicos/Organizados & 506 & 80,3 & 124 & 0,19 & 630 & Cramer's V & 0,232 \\
\hline & Monocráticos/Organizados & 363 & 84,6 & 66 & 0,15 & 429 & $\begin{array}{c}\text { Contingency } \\
\text { Coefficient }\end{array}$ & 0,226 \\
\hline & Pouco organizados & 2210 & 93,3 & 159 & 0,06 & 2369 & $\begin{array}{c}\text { Pearson } \\
\text { Chi-Square } \\
\end{array}$ & 217,762 \\
\hline & Total & 3525 & 87,3 & 513 & 0,12 & 4038 & Sig & 0 \\
\hline
\end{tabular}

Fonte: Elaborada pelos autores com base em dados do TSE. 
A variável "posição do partido" mostra se o partido do candidato era aliado ou não ao partido do governador. O partido "independente" foi aquele que não se coligou a nenhuma chapa majoritária. Esse partido não integrou a coligação governista e nem se aliou a forças oposicionistas na eleição majoritária da UF, embora tenha lançado candidatos em chapas independentes nas eleições proporcionais.

Aqui, verificamos que houve uma vantagem considerável de deputados eleitos por partidos aliados ao governo em seus respectivos estados (17\%), se compararmos com os resultados dos candidatos de partidos oposicionistas na arena subnacional (10\%).

A variável "força política" apresenta a classificação efetuada por Guarnieri (2011) no que tange a organização e controle dos partidos sobre os candidatos lançados ao pleito. Conforme mencionado acima, de acordo com a hipótese do autor, partidos mais organizados e sob influência das lideranças partidárias tendem a lançar menos candidatos sem efetiva chance de êxito eleitoral. Entretanto, contrariando os achados de Guarnieri, foram os partidos poliárquicos aqueles que lograram maior percentual de eleitos no quadro geral de candidaturas para deputado federal em 2010, elegendo quase $27 \%$ dos seus candidatos em face de um escore de $15,4 \%$ dos partidos monocráticos.

No que diz respeito à organização, partidos pouco organizados apresentam percentuais de eleição bastante inferiores $(6,7 \%)$, confirmando, nesse aspecto, a hipótese do autor. Cabe ressaltar, porém, que os índices de associação, embora significativos, são fracos, e que os achados de Guarnieri referem-se às candidaturas majoritárias.

Tabela 13

Descrição das variáveis socioeconômicas

\begin{tabular}{|c|c|c|c|c|c|c|c|c|}
\hline Variável & Categoria & $\begin{array}{c}\text { Não } \\
\text { eleito }\end{array}$ & $\%$ & Eleito & $\%$ & Total & $\begin{array}{l}\text { Symmetric } \\
\text { measures }\end{array}$ & Value \\
\hline \multirow{6}{*}{$\begin{array}{l}\text { Disposição } \\
\text { para política } \\
\text { (profissão) }\end{array}$} & $\begin{array}{c}\text { Alta } \\
\text { disposição }\end{array}$ & 1696 & 0,81 & 405 & 0,19 & 2101 & Phi & 0,207 \\
\hline & $\begin{array}{c}\text { Baixa } \\
\text { disposição }\end{array}$ & 726 & 0,96 & 30 & 0,04 & 756 & Cramer's V & 0,207 \\
\hline & $\begin{array}{c}\text { Média } \\
\text { disposição }\end{array}$ & 639 & 0,93 & 48 & 0,07 & 687 & $\begin{array}{c}\text { Contingency } \\
\text { Coefficient }\end{array}$ & 0,203 \\
\hline & $\begin{array}{c}\text { Não } \\
\text { classificado }\end{array}$ & 464 & 0,94 & 30 & 0,06 & 494 & $\begin{array}{l}\text { Pearson Chi- } \\
\text { Square }\end{array}$ & $173,691 a$ \\
\hline & & & & & & & Sig & 0 \\
\hline & Total & 3525 & 0,87 & 513 & 0,13 & 4038 & & \\
\hline
\end{tabular}




\begin{tabular}{|c|c|c|c|c|c|c|c|c|}
\hline Variável & Categoria & $\begin{array}{c}\text { Não } \\
\text { eleito }\end{array}$ & $\%$ & Eleito & $\%$ & Total & $\begin{array}{c}\text { Symmetric } \\
\text { measures }\end{array}$ & Value \\
\hline \multirow{5}{*}{ Escolaridade } & $\begin{array}{c}\text { Abaixo do } \\
\text { ensino } \\
\text { fundamental }\end{array}$ & 118 & 0,98 & 3 & 0,02 & 121 & Phi & 0,169 \\
\hline & $\begin{array}{c}\text { Ensino } \\
\text { fundamental }\end{array}$ & 349 & 0,94 & 22 & 0,06 & 371 & Cramer's V & 0,169 \\
\hline & Ensino médio & 1195 & 0,93 & 89 & 0,07 & 1284 & $\begin{array}{c}\text { Contingency } \\
\text { Coefficient }\end{array}$ & 0,166 \\
\hline & $\begin{array}{l}\text { Ensino } \\
\text { superior }\end{array}$ & 1863 & 0,82 & 399 & 0,18 & 2262 & $\begin{array}{c}\text { Pearson Chi- } \\
\text { Square }\end{array}$ & $115,015 a$ \\
\hline & Total & 3525 & 0,87 & 513 & 0,13 & 4038 & Sig & 0 \\
\hline \multirow{5}{*}{ Sexo } & Feminino & 601 & 0,93 & 45 & 0,07 & 646 & Phi & 0,075 \\
\hline & Masculino & 2924 & 0,86 & 468 & 0,14 & 3392 & Cramer's V & 0,075 \\
\hline & & & & & & & $\begin{array}{c}\text { Contingency } \\
\text { Coefficient }\end{array}$ & 0,075 \\
\hline & & & & & & & $\begin{array}{c}\text { Pearson Chi- } \\
\text { Square }\end{array}$ & $22,834 a$ \\
\hline & Total & 3525 & 0,87 & 513 & 0,13 & 4.038 & Sig & 0 \\
\hline \multirow{6}{*}{ Região } & Centro-Oeste & 253 & 0,86 & 41 & 0,14 & 294 & Phi & 0,129 \\
\hline & Nordeste & 619 & 0,80 & 151 & 0,20 & 770 & Cramer's V & 0,129 \\
\hline & Norte & 315 & 0,83 & 65 & 0,17 & 380 & $\begin{array}{c}\text { Contingency } \\
\text { Coefficient }\end{array}$ & 0,128 \\
\hline & Sudeste & 1.839 & 0,91 & 179 & 0,09 & 2.018 & $\begin{array}{c}\text { Pearson Chi- } \\
\text { Square }\end{array}$ & $67,137 a$ \\
\hline & Sul & 499 & 0,87 & 77 & 0,13 & 576 & Sig & 0 \\
\hline & Total & 3.525 & 0,87 & 513 & 0,13 & 4.038 & & \\
\hline \multirow{5}{*}{$\begin{array}{l}\text { Magnitude } \\
\text { do distrito }\end{array}$} & $\begin{array}{c}\text { Alta } \\
\text { magnitude }\end{array}$ & 1.918 & 0,90 & 208 & 0,10 & 2126 & Phi & 0,093 \\
\hline & $\begin{array}{c}\text { Baixa } \\
\text { magnitude }\end{array}$ & 696 & 0,84 & 129 & 0,16 & 825 & Cramer's V & 0,093 \\
\hline & $\begin{array}{c}\text { Média } \\
\text { magnitude }\end{array}$ & 911 & 0,84 & 176 & 0,16 & 1.087 & $\begin{array}{c}\text { Contingency } \\
\text { Coefficient }\end{array}$ & 0,092 \\
\hline & & & & & & & $\begin{array}{c}\text { Pearson Chi- } \\
\text { Square }\end{array}$ & $34,666 a$ \\
\hline & Total & 3.525 & 0,87 & 513 & 0,13 & 4.038 & Sig & 0 \\
\hline
\end{tabular}

Fonte: Elaborada pelos autores com base em dados do TSE. 
Na Tabela 13 elencamos algumas das variáveis socioeconômicas que a literatura tem apontado como importantes no debate sobre o financiamento de campanha.

$\mathrm{Na}$ descrição da variável "sexo", verificamos que as mulheres se lançaram em menor escala na eleição para deputado federal comparativamente aos homens e, consequentemente, tiveram pouquíssimas cadeiras na Câmara dos Deputados (45). Além disso, os homens tiveram o dobro de taxa de sucesso eleitoral (14\%) das mulheres (7\%), reafirmando a hegemonia masculina no parlamento.

A variável "disposição para política" ${ }^{11}$ busca identificar nas características das ocupações profissionais dos candidatos as tendências de maior ou menor aptidão para a carreira política (Codato, Costa e Massimo, 2014) ${ }^{12}$. Nesse ponto, é importante destacar a significativa quantidade de candidatos com profissões classificadas como de alta disposição para política. Metade (2101) do total de candidatos observados (4038) a deputado federal em 2010 apresentou alta disposição para política. Entre os eleitos essa proporção se elevou: 79\% (405) tinham ocupação profissional classificada como de alta disposição para a política.

As variáveis "região" e "magnitude do distrito" foram incluídas no modelo de regressão logística para verificarmos possíveis efeitos dos padrões de disputa em determinadas regiões e estados do país ${ }^{13}$.

\section{Resultado dos testes}

Findada a análise descritiva levada a cabo na seção anterior, na qual as variáveis independentes foram apresentadas e aproximadas por intermédio de associações diretas, existem já algumas pistas sobre a influência das diferentes formas de despesas sobre os resultados eleitorais. Contudo, essas inferências precisam ser observadas através da análise multivariada que realizamos nesta seção, utilizando modelos de regressão logística e regressão linear multivariada. Os modelos de regressão logística foram construídos da seguinte forma: 1) apenas as variáveis de despesas de campanha; 2) variáveis de despesas de campanha e variáveis socioeconômicas; 3) variáveis de despesas de campanha e variáveis políticas; e 4) variáveis de despesas de campanha; variáveis socioeconômicas e variáveis políticas.

\footnotetext{
${ }^{11}$ Essa classificação combina as características de: a) carreira flexível; b) status social; e c) afinidade com a atividade política. Carreiras profissionais que combinem simultaneamente essas três características configurariam uma alta disposição para a política.

12 Agradecemos gentilmente aos autores por terem nos encaminhado a codificação das ocupações profissionais para que pudéssemos replicá-la neste artigo.

${ }^{13}$ A literatura indica que "a receita média dos candidatos é menor nos distritos em que há mais cadeiras em disputa" (Mancuso, 2015, p. 23). Segundo Mancuso (2015), ao abordar a eleição para as Câmaras de Vereadores no país no ano de 2008, Peixoto (2012) constatou que, na medida em que ocorre o aumento do número de assentos em disputas nos parlamentos municipais, cresce também o custo médio, por eleitor, das eleições majoritárias e proporcionais nos municípios brasileiros.
} 
Tabela 14

Testes de especificação e ajuste dos modelos

\begin{tabular}{|l|c|c|c|c|c|c|}
\hline & \multicolumn{2}{|c|}{ Overall statistics } & \multicolumn{2}{c|}{$\begin{array}{c}\text { Omnibus Tests of } \\
\text { Model Coefficients }\end{array}$} & \multicolumn{2}{c|}{$\begin{array}{c}\text { Hosmer and } \\
\text { Lemeshow Test }\end{array}$} \\
\hline & Score & Sig. & Chi-Square & Sig. & Chi-Square & Sig. \\
\hline Modelo 1 & 1912,986 &, 000 & 1659,611 &, 000 & 3,789 &, 876 \\
\hline Modelo 2 & 2003,449 &, 000 & 1792,418 &, 000 & 3,894 &, 867 \\
\hline Modelo 3 & 2159,683 &, 000 & 1807,558 &, 000 & 1,809 &, 986 \\
\hline Modelo 4 & 22010,69 &, 000 & 1878,511 &, 000 & 2,955 &, 937 \\
\hline
\end{tabular}

Fonte: Tabela elaborada pelos autores.

Na Tabela 14 testamos a estatística global "Overall" por meio do chi-quadrado dos resíduos. Os valores estatisticamente significativos nesse teste nos informam que as variáveis excluídas do modelo não contribuiriam de forma significativa. De acordo com essa tabela, o modelo foi o que apresentou maior valor, sendo mais completo não somente em número de variáveis, mas também em seu valor preditivo.

Também testamos a especificação e o ajuste dos modelos por meio de testes utilizando o chi-square. O primeiro "Omnibus" confirmou que ao menos um dos coeficientes do modelo foi diferente de zero. E o segundo, "Hosmer and Lemeshow", avaliou o seu poder preditivo do modelo. Em todos os modelos os índices foram satisfatórios.

Tabela 15

Testes de adequação do modelo

\begin{tabular}{|l|c|c|c|}
\hline & $\mathbf{- 2}$ Log likelihood & $\begin{array}{c}\text { Cox \& Snell R } \\
\text { square }\end{array}$ & $\begin{array}{c}\text { Nagelkerke R } \\
\text { square }\end{array}$ \\
\hline Modelo 1 & 1415,139 &, 337 &, 632 \\
\hline Modelo 2 & 1282,332 &, 358 &, 673 \\
\hline Modelo 3 & 1267,192 &, 361 &, 677 \\
\hline Modelo 4 & 1196,239 &, 372 &, 698 \\
\hline
\end{tabular}

Fonte: Elaborada pelos autores.

Na regressão logística, para atestarmos a adequação do modelo, utilizamos os "pseudos" $r^{2}$. Quanto mais próximo de 1 os coeficientes de Cox \& Snell $r^{2}$ e Nagelkerk $r^{2}$ estiverem, melhor a adequação do modelo. Isso indica que os modelos testados foram consistentes e o teste tornou-se mais robusto no modelo 4, no qual as variáveis de gastos de campanha foram agregadas às variáveis políticas e socioeconômicas.

Sobre o parâmetro "-2 Log Likelihood", quanto menor o índice, melhor para o modelo. 0 modelo 4, nesse sentido, foi o que expressou maior capacidade preditiva em comparação aos demais modelos. 
Um aspecto importante é que tanto na Tabela 6 quanto na Tabela 7 os valores mais significativos foram referentes ao modelo 4 . E entre os modelos 2 e 3, este último, que agregou apenas as variáveis políticas, obteve valores mais robustos embora muito próximos um do outro em termos de significância.

Antes de mostrar os resultados dos modelos de regressão logística, elencamos as variáveis que não foram estatisticamente significativas nos testes.

Tabela 16

Variáveis que não foram estatisticamente significativas nos testes de regressão logística

\begin{tabular}{|c|c|c|c|}
\hline $\begin{array}{c}\text { Gastos ponderados } \\
\text { por UF }\end{array}$ & $\begin{array}{c}\text { Gastos } \\
\text { ponderados por } \\
\text { candidato }\end{array}$ & $\begin{array}{c}\text { Variáveis } \\
\text { socioeconômicas }\end{array}$ & $\begin{array}{c}\text { Variáveis } \\
\text { políticas }\end{array}$ \\
\hline Despesa doações & Despesa doações & Escolaridade & Ideologia \\
\hline Despesa pessoal & Despesa pessoal & Sexo & $\begin{array}{c}\text { Posição do } \\
\text { Partido }\end{array}$ \\
\hline $\begin{array}{c}\text { Despesa } \\
\text { comunicação }\end{array}$ & Despesa outros & Região & \\
\hline & Despesa estrutura & & \\
\hline
\end{tabular}

Fonte: Tabela elaborada pelos autores.

Dentre as variáveis de despesas de campanha testadas, vimos que tanto as despesas de "doações a outros candidatos e partidos" quanto os gastos com "pessoal", ponderados pelo total da UF ou pelo gasto total do candidato, não foram estatisticamente significativos em nenhum modelo. Não apresentaram influência na probabilidade de o candidato ser ou não eleito, embora gastos consideráveis tenham sido percebidos nessas rubricas $^{14}$. Quanto aos gastos ponderados por UF, as despesas em "comunicação" não apresentaram influência no teste de regressão logística.

Por outro lado, quando ponderados por candidato, os gastos em "comunicação e publicidade" apresentam valores estatisticamente significativos. Candidatos que apresentam maiores despesas em "comunicação" possuem até 11 vezes mais chances de eleição em relação a candidatos que apresentam menores despesas.

Os testes também mostraram que as variáveis políticas "ideologia" e "posição do partido", bem como as variáveis socioeconômicas "escolaridade" e "sexo", não foram significativas para influenciar as razões de chances de os candidatos serem eleitos, quando incluímos as variáveis de despesas de campanha.

\footnotetext{
${ }^{14}$ No Gráfico 1 vimos que as despesas com "pessoal" foram de $20 \%$ para não eleitos e $25 \%$ para eleitos. E as "doações a outros candidatos" ficaram em $6 \%$ para não eleitos e $5 \%$ para eleitos.
} 
Tabela 17

Análise multivariada - Regressão logística binomial

\begin{tabular}{|c|c|c|c|c|c|c|c|c|c|c|c|c|c|}
\hline \multirow{2}{*}{$\begin{array}{c}\text { Variável } \\
\text { independente }\end{array}$} & \multirow{2}{*}{ Categoria } & \multicolumn{3}{|c|}{ Modelo 1} & \multicolumn{3}{|c|}{ Modelo 2} & \multicolumn{3}{|c|}{ Modelo 3} & \multicolumn{3}{|c|}{ Modelo 4} \\
\hline & & Wald & Sig. & $\operatorname{Exp}(B)^{15}$ & Wald & Sig. & $\operatorname{Exp}(B)$ & Wald & Sig. & $\operatorname{Exp}(B)$ & Wald & Sig. & $\operatorname{Exp}(B)$ \\
\hline \multirow[b]{2}{*}{$\begin{array}{l}\text { Despesa } \\
\text { outros (UF) }\end{array}$} & Sem despesa & \multicolumn{2}{|l|}{ Referência } & & \multicolumn{2}{|l|}{ Referência } & & \multicolumn{2}{|c|}{ Referência } & & \multicolumn{2}{|l|}{ Referência } & \\
\hline & $\begin{array}{l}\text { Maiores } \\
\text { despesas }\end{array}$ & 3,476 &, 062 & 3,048 & 8,118 &, 004 & 6,495 & 4,463 & ,035 & 4,243 & 7,436 &, 006 & 7,340 \\
\hline \multirow{3}{*}{$\begin{array}{l}\text { Despesa } \\
\text { estrutura (UF) }\end{array}$} & Sem despesa & Referência & & & Referência & & & \multicolumn{2}{|c|}{ Referência } & & Referência & & \\
\hline & $\begin{array}{l}\text { Despesas } \\
\text { médias altas }\end{array}$ & 4,941 & ,026 & 3,547 & 4,250 & ,039 & 3,465 & 2,909 & ,088 & 2,795 & 3,418 & , 064 & 3,149 \\
\hline & $\begin{array}{l}\text { Maiores } \\
\text { despesas }\end{array}$ & 14,358 & ,000 & 10,644 & 13,009 & ,000 & 10,861 & 8,885 & ,003 & 7,153 & 10,129 & ,001 & 8,763 \\
\hline \multirow{3}{*}{$\begin{array}{l}\text { Despesa total } \\
\text { (UF) }\end{array}$} & $\begin{array}{l}\text { Menores } \\
\text { despesas }\end{array}$ & \multicolumn{2}{|l|}{ Referência } & & \multicolumn{2}{|l|}{ Referência } & & \multicolumn{2}{|c|}{ Referência } & & \multicolumn{2}{|l|}{ Referência } & \\
\hline & $\begin{array}{l}\text { Despesas } \\
\text { médias altas }\end{array}$ & 2,984 & , 084 & 3,768 & 5,112 & , 024 & 6,671 & 4,137 & ,042 & 4,709 & 5,513 & ,019 & 6,831 \\
\hline & $\begin{array}{l}\text { Maiores } \\
\text { despesas }\end{array}$ & 7,480 & ,006 & 8,901 & 8,993 & ,003 & 13,768 & 8,246 & ,004 & 9,859 & 8,822 & ,003 & 12,624 \\
\hline \multirow{4}{*}{$\begin{array}{l}\text { Despesa } \\
\text { comunicação } \\
\text { (cand.) }\end{array}$} & Sem despesa & \multicolumn{2}{|l|}{ Referência } & & \multicolumn{2}{|l|}{ Referência } & & \multicolumn{2}{|c|}{ Referência } & & \multicolumn{2}{|l|}{ Referência } & \\
\hline & \begin{tabular}{|l} 
Despesas \\
médias \\
baixas \\
\end{tabular} & 4,474 & , 034 & 7,485 & 2,314 &, 128 & 4,546 & 5,175 & ,023 & 9,707 & 2,898 & , 089 & 6,057 \\
\hline & $\begin{array}{l}\text { Despesas } \\
\text { médias altas }\end{array}$ & 5,407 & ,020 & 9,462 & 2,482 & ,115 & 4,899 & 6,346 & ,012 & 12,801 & 3,275 & , 070 & 6,951 \\
\hline & $\begin{array}{l}\text { Maiores } \\
\text { despesas }\end{array}$ & 7,471 &, 006 & 15,776 & 4,028 & , 045 & 8,261 & 8,295 & ,004 & 20,837 & 4,721 &, 030 & 11,264 \\
\hline \multirow{2}{*}{$\begin{array}{l}\text { Padrão de } \\
\text { gastos (cand.) }\end{array}$} & $\begin{array}{l}\text { Recursos } \\
\text { concentrados }\end{array}$ & \multicolumn{2}{|l|}{ Referência } & & \multicolumn{2}{|l|}{ Referência } & & \multicolumn{2}{|c|}{ Referência } & & \multicolumn{2}{|l|}{ Referência } & \\
\hline & $\begin{array}{l}\text { Recursos } \\
\text { pulverizados }\end{array}$ & 2,940 & , 086 & ,592 & 3,802 & , 051 &, 527 & 4,197 & ,041 & ,498 & 5,033 & , 025 & ,453 \\
\hline \multirow{3}{*}{$\begin{array}{l}\text { Disposição } \\
\text { para política } \\
\text { (profissão) }\end{array}$} & $\begin{array}{l}\text { Alta } \\
\text { disposição }\end{array}$ & & & & \multicolumn{2}{|l|}{ Referência } & & & & & Referência & & \\
\hline & $\begin{array}{l}\text { Baixa } \\
\text { disposição }\end{array}$ & & & & 4,794 & ,029 & ,553 & & & & ,496 & ,481 & ,821 \\
\hline & $\begin{array}{l}\text { Média } \\
\text { disposição }\end{array}$ & & & & 15,363 & ,000 &, 418 & & & & 4,459 & ,035 &, 610 \\
\hline & $\begin{array}{l}\text { Alta } \\
\text { magnitude }\end{array}$ & & & & Referência & & & & & & Referência & & \\
\hline $\begin{array}{l}\text { Magnitude do } \\
\text { distrito }\end{array}$ & $\begin{array}{l}\text { Baixa } \\
\text { magnitude }\end{array}$ & & & & 37,829 & , 000 & , 150 & & & & 26,331 &, 000 & ,171 \\
\hline & $\begin{array}{l}\text { Média } \\
\text { magnitude }\end{array}$ & & & & 8,858 & ,003 & ,384 & & & & 8,043 & ,005 & ,364 \\
\hline & Desafiante & & & & & & & Referênci & & & Referência & & \\
\hline Força polıtıca & Incumbent & & & & & & & 116,129 &, 000 & 6,278 & 72,022 &, 000 & 4,668 \\
\hline & Constant & 48,182 &, 000 &, 000 & 28,933 &, 000 &, 000 & 44,316 &, 000 &, 000 & 29,339 &, 000 &, 000 \\
\hline
\end{tabular}

Fonte: Elaborada pelos autores com base em dados do TSE.

Método Enter. Variável dependente: Resultado eleitoral 2010. Eleito (1); Não eleito (0).

No modelo 1, no qual comparamos apenas as variáveis de despesas de campanha, temos um resultado que contraria o senso comum. O teste indica que os candidatos com maiores gastos em "estrutura", comparativamente aos seus concorrentes, tiveram 10,6 vezes mais chances de ser eleitos do que os candidatos com os maiores gastos totais do estado $(8,9)$.

15 O sinal do coeficiente informa o sentido da relação de causalidade. Na apresentação dos resultados, optamos por analisar o valor da função exponencial aplicada a cada coeficiente (Exp B), que representa a razão da chance de eleição do candidato, entre indivíduos da categoria em pauta, "descontando" o efeito das outras variáveis do modelo. 
Assim, a chamada "corrida armamentista" (Duschinsky, 2002) por dinheiro, baseada na crença de que a arrecadação por si só seria a causa do melhor desempenho eleitoral, pode ser apenas um fator que inflaciona o custo das eleições, em vez de efetivamente resultar em êxito político. Embora nos modelos 2, 3 e 4 o volume de dinheiro tenha maior efeito.

Vimos também na Tabela 17 que as despesas ponderadas pelo candidato foram estatisticamente significativas apenas para os gastos em "comunicação e publicidade". Entre os que destinaram maiores recursos nesse tipo de despesa, a razão de chance chegou a ser de 15,7 vezes maior se comparada aos que não tiveram gasto em "comunicação".

No modelo 2, quando agregamos as variáveis socioeconômicas, as maiores despesas em "outros gastos" obtiveram significância estatística. Os candidatos que tiveram maiores despesas desse tipo foram 6,5 vezes mais propensos a ser eleitos do que aqueles que detalharam todos os seus recursos.

Além disso, nesse modelo, as candidaturas com os maiores gastos totais, em comparação aos seus competidores, tiveram 13,8 vezes mais chances de êxito do que aqueles com menores recursos, embora os gastos em "estrutura" também fiquem próximos desse resultado $(10,9)$. Os gastos ponderados pela UF dos tipos "pessoal", "comunicação" e "doações a outros candidatos" não tiveram significância estatística.

Quanto às despesas ponderadas pelos candidatos, os competidores com maiores gastos em "comunicação" apresentaram 8,3 vezes mais chances de serem eleitos. Além disso, a variável "padrão de gastos" foi estatisticamente significante, indicando que o padrão de gastos pulverizados dos candidatos não foi uma boa estratégia para ser eleito. Candidatos que diversificaram muito suas despesas apresentaram um decréscimo de quase $50 \%$ de razão de chance em comparação aos concorrentes com gastos mais concentrados em um tipo apenas.

Com relação às variáveis socioeconômicas, as que tiveram significância estatística foram "magnitude do distrito" e "disposição para a política". Candidatos dos menores estados incorrem em perda de $85 \%$ da possibilidade de serem eleitos em comparação aos dos maiores distritos, e os dos distritos médios em cerca $60 \%$, quando são testadas em conjunto com as variáveis de despesas de campanha no modelo de regressão logística.

Por outro lado, as profissões que apresentam maior disposição para a política confirmaram sua força no modelo. Os candidatos com ocupações profissionais de baixa e média disposição para política tiveram um decréscimo de, respectivamente, 55\% e 42\% da razão de chance de serem eleitos em comparação aos seus concorrentes com profissões de alta disposição para a política.

No modelo 3 as mesmas variáveis de despesas dos modelos anteriores também foram estatisticamente significantes. A diferença é que, enquanto em relação aos gastos ponderados por UF os valores de razão de chance diminuíram de 6,5 para 4,2 para 
"outros gastos", de 10,9 para 7,1 para "estrutura" e de 13,8 para 9,8 para as "despesas totais", a razão de chance dos gastos ponderadas por candidato aumentou significativamente para despesas em "comunicação", saltando de 8,3 do modelo 2 para 20,8 no modelo 3.

Tal discrepância pode nos levar a crer que as despesas em "comunicação" tenham maior resposta quando relacionadas a variáveis políticas, diferentemente do volume de "gastos em estrutura", os quais poderiam ser mais associados a fatores controlados por variáveis sociais e econômicas.

Ainda no modelo 3, a única variável política com significância estatística foi a "força política" do candidato, reforçando os achados da literatura ao predizer que o incumbent teve 6,3 vezes mais chances de ser eleito do que o desafiante para deputado federal.

No último modelo, agregamos as variáveis políticas e socioeconômicas aos gastos de campanha.

Nesse modelo, os candidatos com profissões de alta disposição para política se mantiveram com maior razão de chance de serem eleitos, visto que os competidores de média disposição apresentaram um decréscimo de $40 \%$ em relação a essa probabilidade. A maior magnitude do distrito também apresentou significância estatística, com valores bem próximos aos do modelo 2, quando também foi testada. E os incumbents apresentaram 4,7 mais chances de serem eleitos do que os desafiantes, caindo um pouco em relação ao modelo $3(6,3)$.

Quanto às variáveis de despesas de campanha ponderadas por UF e por candidato, elas se mantiveram mais próximas do padrão do modelo 2. Os gastos com "estrutura" foram mais influentes do que a variável "outros gastos", embora com valores muito próximos, 8,7 e 7,3 respectivamente. No entanto, os candidatos com as maiores despesas totais tiveram 12,6 vezes mais chances de ser eleitos. Esse valor supera, inclusive, o encontrado para incumbents $(4,7)$, reforçando o argumento de que o encarecimento das campanhas pode ser causado pela expectativa de vitória associada ao volume de dinheiro nas eleições.

No entanto, os valores encontrados no modelo 4 sobre as despesas em "comunicação" ponderadas por candidatos ficaram apenas um pouco abaixo. Ou seja, candidatos que mais destinaram seus recursos para comunicação tiveram 11,3 vezes mais chances de ser eleitos do que os que não tiveram nenhum gasto nessa rubrica. Além disso, o padrão concentrado de gastos de recursos se mostrou mais forte, visto que os candidatos que pulverizaram seus recursos tiveram $55 \%$ menos chances de ser eleitos do que os candidatos que concentraram recursos em apenas um gasto. A variável "força do partido" (Guarnieri, 2011) foi inserida no modelo 4, contudo, o resultado para essa variável não foi estatisticamente significativo, tampouco alterou os escores para as demais variáveis do modelo.

Outra forma para testar as hipóteses deste artigo foi levada a cabo para apurar o 
resultado eleitoral de forma alternativa à mera apresentação dicotômica (eleito/não eleito). Para tanto, tomaram-se os votos de forma contínua, testando-se as hipóteses por meio da análise de regressão linear multivariada. Nesse modelo, apuramos o efeito de cada uma das despesas sobre o resultado eleitoral, controlando: a) pela magnitude do colégio eleitoral; e b) pela força do partido, nesse caso, testando por essa via a hipótese de Guarnieri nas eleições para deputados federais. Apenas as variáveis que apresentaram significância estatística acima de um intervalo de confiança de $95 \%$ são relatadas.

Na Tabela 18 infere-se que as despesas em "comunicação" e "estrutura" são as mais relevantes para distritos eleitorais de alta magnitude. Nesse caso, se considerássemos uma despesa hipotética de R\$ 100 mil em "comunicação", aplicando-se os coeficientes apurados na fórmula da regressão linear $\left(y=a \cdot x+b^{16}\right)$, poder-se-ia predizer uma votação de 38.249 votos, com o valor médio por voto de $R \$ 2,61$. Ao passo que a mesma despesa na rubrica "estrutura" produziria uma votação de 45.549 com o valor médio de $\mathrm{R} \$ 2,20$ por voto. Pode-se deduzir assim que os gastos em "estrutura" se revertem em mais votos do que os gastos em "comunicação" para distritos de alta magnitude eleitoral. Contudo, os escores de correlação são mais fortes para despesas em "comunicação" do que em "estrutura".

Nos distritos de média magnitude eleitoral os resultados são similares, variandose apenas os escores. O valor médio por voto com despesas em "comunicação" passa a ser de $R \$ 1,54$, e de $R \$ 1,45$ com despesas em "estrutura". Esses dados confirmam achados da literatura (Peixoto, 2012; Heiler, 2014) que demonstram que o tamanho do distrito eleitoral interfere sobre a dependência dos candidatos em relação ao dinheiro.

\section{Tabela 18}

Regressão linear - Votos para deputado federal 2010 segundo diferentes tipos de gastos, controlados pela magnitude do distrito eleitoral

\begin{tabular}{|c|c|c|c|c|c|c|c|c|}
\hline \multirow{2}{*}{$\begin{array}{l}\text { Magnitude } \\
\text { distrito } \\
\text { eleitoral }\end{array}$} & \multirow[t]{2}{*}{ Despesa } & \multicolumn{2}{|c|}{$\begin{array}{l}\text { Unstandardized } \\
\text { coefficients }\end{array}$} & \multirow{2}{*}{$\begin{array}{c}\begin{array}{c}\text { Standarded } \\
\text { coefficients }\end{array} \\
\text { Beta }\end{array}$} & \multirow[t]{2}{*}{$\mathbf{T}$} & \multirow{2}{*}{$\begin{array}{l}\text { Sig. } \\
(95 \%)\end{array}$} & \multirow[t]{2}{*}{$\mathbf{R}$} & \multirow{2}{*}{$\begin{array}{c}\mathbf{R} \\
\text { Square }\end{array}$} \\
\hline & & B & Std. Error & & & & & \\
\hline \multirow{4}{*}{ Alta } & (Constant) & 33249,021 & 7129,733 & & 4,663 & ,000 & \multirow{4}{*}{0,593} & \multirow{4}{*}{,351 } \\
\hline & Comunicação & ,050 & ,011 & ,370 & 4,654 &, 000 & & \\
\hline & Estrutura & 123 & ,031 & ,294 & 3,993 &, 000 & & \\
\hline & Outros & , 107 & ,046 & , 155 & 2,315 &, 022 & & \\
\hline \multirow{4}{*}{ Média } & (Constant) & 60337,879 & 7508,157 & & 8,036 & ,000 & \multirow{4}{*}{,418 } & \multirow{4}{*}{ 175 } \\
\hline & Comunicação & ,048 & ,018 &, 303 & 2,682 &, 008 & & \\
\hline & Estrutura &, 087 & 046 & 232 & 1,906 & 059 & & \\
\hline & Pessoal &,- 038 &, 020 &,- 217 & $-1,969$ &, 051 & & \\
\hline \multirow{2}{*}{ Baixa } & (Constant) & 28838,762 & 7344,999 & & 3,926 & ,000 & \multirow{2}{*}{, 470 } & \multirow{2}{*}{,220 } \\
\hline & Comunicação & 057 &, 021 & 330 & 2,703 & ,008 & & \\
\hline
\end{tabular}

Fonte: Elaborada pelos autores com base em dados do TSE.

16 Onde y é a variável dependente, a ser predita, nesse caso, votos; a = coeficiente de inclinação, representado por $B$ na tabela, e $b=$ intercepto, representado pela constante em $B$, e $x$ é o valor estimado em despesas, nesse exemplo, R\$100 mil. 
Na Tabela 19 testamos a dependência do resultado eleitoral de diferentes tipos de despesas controlando-se pela força do partido. De acordo com a teoria de Guarnieri, seria de esperar que partidos mais organizados e centralizados teriam um melhor aproveitamento do dinheiro em relação a outros partidos.

Infere-se nos resultados apresentados que a despesa mais relevante em todos os casos é aquela efetuada para cobrir gastos com "comunicação e publicidade". Além disso, confirma-se a hipótese de Guarnieri, para quem partidos mais centralizados e organizados teriam maior controle sobre as candidaturas, o que, nesse caso, redundaria em campanhas com melhor aproveitamento de recursos, conforme se infere abaixo. Considerando a despesa hipotética de $\mathrm{R} \$ 100 \mathrm{mil}$ em comunicação, aplicando-se os coeficientes apurados na fórmula da regressão linear $(y=a \cdot x+b)$, poder-se-ia predizer as seguintes votações:

Partidos poliárquicos/organizados: 54.784 votos $-R \$ 1,83 /$ voto Partidos oligárquicos/organizados: 49.947 votos $-R \$ 2,00 /$ voto Partidos monocráticos/organizados: 63.522 votos $-R \$ 1,57 /$ voto Partidos pouco organizados: 28.945 votos $-R \$ 3,45 /$ voto

Dessa forma infere-se que em partidos pouco organizados e partidos cuja centralidade decisória é pouco eficiente, caso dos partidos poliárquicos, os gastos têm um menor aproveitamento. Portanto, além de ser possível afirmar que despesas em "comunicação" e "estrutura" são as melhores preditoras do voto, também se pode afirmar que a força do partido, tal como teorizada por Guarnieri (2011), importa.

Tabela 19

Regressão linear - Votos para deputado federal em 2010 segundo diferentes tipos de gastos, controlados pela força do partido ${ }^{17}$

\begin{tabular}{|c|c|c|c|c|c|c|c|c|}
\hline \multirow{2}{*}{$\begin{array}{c}\text { Força do } \\
\text { partido }\end{array}$} & \multirow{2}{*}{$\begin{array}{l}\text { Espécie } \\
\text { despesa }\end{array}$} & \multicolumn{2}{|c|}{$\begin{array}{c}\text { Unstandardized } \\
\text { coefficients }\end{array}$} & \multirow{2}{*}{$\begin{array}{l}\text { Standardized } \\
\text { coefficients } \\
\text { Beta }\end{array}$} & \multirow[t]{2}{*}{$\mathbf{t}$} & \multirow{2}{*}{$\begin{array}{l}\text { Sig. } \\
(95 \\
\%)\end{array}$} & \multirow[t]{2}{*}{$\mathbf{R}$} & \multirow{2}{*}{$\begin{array}{c}\mathbf{R} \\
\text { Square }\end{array}$} \\
\hline & & $B$ & Std. Error & & & & & \\
\hline \multirow{3}{*}{$\begin{array}{l}\text { Poliárquicos/ } \\
\text { Organizados }\end{array}$} & (Constant) & \begin{tabular}{|l|}
51184,165 \\
\end{tabular} & 8548,699 & & 5,987 &, 000 & \multirow{3}{*}{,479 } & \multirow{3}{*}{ 229 } \\
\hline & Comunicação &, 036 & 012 & 308 & 2,907 & ,004 & & \\
\hline & Outros & 143 & 050 & 263 & 2,841 & 005 & & \\
\hline \multirow{4}{*}{$\begin{array}{l}\text { Oligárquicos/ } \\
\text { Organizados }\end{array}$} & (Constant) & 45347,176 & 7309,803 & & 6,204 &, 000 & \multirow{4}{*}{ 638 } & \multirow{4}{*}{,407 } \\
\hline & Comunicação &, 046 &, 012 & , 422 & 3,812 &, 000 & & \\
\hline & Estrutura & 097 &, 034 & 300 & 2,830 &, 006 & & \\
\hline & Outros &,- 059 & 021 &,- 252 & 2,849 & 005 & & \\
\hline \multirow{2}{*}{$\begin{array}{l}\text { Monocráticos/ } \\
\text { Organizados }\end{array}$} & (Constant) & 52822,511 & 19415,252 & & 2,721 & 009 & \multirow{2}{*}{,449 } & \multirow{2}{*}{,202 } \\
\hline & Comunicação & , 107 &, 037 & ,448 & 2,861 &, 006 & & \\
\hline \multirow{4}{*}{$\begin{array}{l}\text { Pouco } \\
\text { Organizados }\end{array}$} & (Constant) & 21645,453 & 6593,394 & & 3,283 &, 001 & \multirow{4}{*}{ 571 } & \multirow{4}{*}{,326 } \\
\hline & Comunicação & ,073 &, 021 & ,391 & 3,414 & ,001 & & \\
\hline & Estrutura & 124 & ,041 & 277 & 3,067 &, 003 & & \\
\hline & Outros & 170 & 052 & 251 & 3,257 & 001 & & \\
\hline
\end{tabular}

Fonte: Elaborada pelos autores com base em dados do TSE.

\footnotetext{
17 Elaborada de acordo com classificação apresentada por Guarnieri (2011).
} 


\section{Considerações finais}

Acreditamos que este artigo conseguiu avançar nas duas questões propostas na Introdução. Vimos claramente que os gastos em "estrutura" (volume de despesa) e em "comunicação" (padrão de despesa) tiveram muito mais influência, sendo melhores preditores do resultado eleitoral, do que os outros tipos de dispêndios. Dentre as variáveis de controle, os competidores eleitoralmente mais fortes foram os incumbents e os candidatos com ocupações de alta disposição para política. Além disso, candidatos oriundos de partidos mais bem organizados e sob controle centralizado possuem maior aproveitamento dos recursos que candidatos que concorrem por partidos que não possuem essas características.

A primeira hipótese do artigo foi confirmada, visto que os montantes de gastos em "estrutura" e "comunicação" apresentaram-se com os melhores escores preditores do sucesso eleitoral quando tomados em sua forma dicotômica (eleito/não eleito) ou contínua, adotando-se as votações obtidas pelos candidatos.

Com respeito à segunda hipótese, na qual inferimos sobre um padrão equilibrado em diversas despesas, não encontramos o esperado, visto que os gastos concentrados foram os que tiveram maior significância. Acreditávamos que gastos balanceados em diversos tipos de despesa poderiam indicar maior probabilidade de os candidatos possuírem máquinas de campanha mais robustas e, por consequência, maior sucesso eleitoral.

Diante dos resultados encontrados, podemos dizer que a pesquisa revelou não apenas a necessidade dos candidatos por maiores volumes de recursos, mas também por uma forte demanda em "comunicação" e "estrutura". A máquina de campanha precisa estar no mesmo nível dos competidores com maior acesso a financiamento. Em outras palavras, quanto maior o montante de gastos nessas rubricas no seu distrito eleitoral, maior a necessidade de o candidato acompanhar essa tendência. Supomos que o nível de profissionalização deva ser muito elevado, justamente pelos valores mais significativos terem sido encontrados tanto para "estrutura" quanto para "comunicação". Enquanto os gastos com "pessoal", ou cabos eleitorais, não apresentaram influência nas razões de chance de os candidatos serem eleitos.

Em resumo, o principal achado reside na percepção de que somente o volume de dinheiro não basta para explicar o sucesso eleitoral. Os modelos demonstraram que o padrão de gasto precisa ser concentrado e que as maiores despesas devem ser destinadas para "comunicação e publicidade". Com isso, pode-se afirmar que o fato de o candidato ter maiores recursos não significa necessariamente que tenha maiores chances de sucesso eleitoral. Nem que deva gastar a maior parte do seu dinheiro em "estrutura" ou "comunicação". Mas significa que precisa ter um volume de recursos suficiente nessas rubricas para sua campanha ser mais competitiva.

De todo modo, o dinheiro ainda importa. As candidaturas precisam ter um volume de recursos muito acima da média dos demais competidores para que consigam 
se enquadrar nos achados do modelo. E, por sua vez, a maior fonte capaz de suprir essa alta demanda por uma máquina de campanha competitiva ainda é o empresariado. Resta saber como o novo modelo eleitoral aprovado na reforma política (Lei 13.165/2015) pode alterar esses achados.

Além disso, importa destacar que candidatos que disputam eleições em partidos mais organizados e com um grau de coordenação mais centralizado estão em melhores condições do que seus concorrentes. Esses candidatos possuem melhor taxa de aproveitamento dos recursos empregados. Achado que se alinha conforme hipótese originalmente apresentada por Guarnieri (2011) no que tange à seleção e à coordenação de campanhas eleitorais.

Finalmente, observando o alto montante e a significância estatística dos "outros gastos", verificamos que essa foi uma característica comum, principalmente entre os candidatos com maiores recursos, demonstrando que a transparência em campanhas muito caras não foi uma característica da maioria dessas candidaturas. Nesse sentido, apontamos que o Sistema de Prestação de Contas Eleitorais (SPCE) precisaria ser aperfeiçoado de modo a reduzir a possibilidade do lançamento de prestações de contas genéricas para que as campanhas sejam cada vez mais transparentes.

Jeison Giovani Heiler - Doutorando em Ciência Política. Departamento de Ciência Política, Universidade Estadual de Campinas (Unicamp). Docente na Católica-SC. Email: <jeisonheiler@gmail.com>.

João Paulo Saraiva Leão Viana - Doutorando em Ciência Política. Departamento de Ciência Política, Universidade Estadual de Campinas (Unicamp). Professor de Ciência Política da Universidade Federal de Rondônia (Unir). Email: <joaopauloviana@hotmail.com>.

Rodrigo Dolandeli dos Santos - Doutorando em Ciência Política. Departamento de Ciência Política, Universidade Estadual de Campinas (Unicamp). O autor é bolsista CNPq. Email: <dolandeli@gmail.com>.

\section{Referências bibliográficas}

BARBETtA, P. A. Estatística aplicada às ciências sociais. 5a ed. Florianópolis: Editora da UFSC, 2004. Disponível em: <http://www.inf.ufsc.br/ barbetta/livro1.htm>. Acesso em: 10 out. 2010.

Cervi, E. U. "Financiamento de campanhas e desempenho eleitoral no Brasil: análise das contribuições de pessoas físicas, jurídicas e partidos políticos às eleições de 2008 nas capitais de estado". Revista Brasileira de Ciência Política, Brasília, no 4, p. 135-167, jul.-dez. 2010.

CodAto, A; CostA, L. D.; MASSimo, L. "Classificando ocupações prévias à entrada na política: uma discussão metodológica e um teste empírico". Opinião Pública, Campinas, vol. 20, no 3, p. 346-362, dez. 2014. Disponível em: <http://www.scielo.br/scielo.php?script=sci_arttext\&pid=S010462762014000300346\&lng=en\&nrm=iso>. Acesso em: 28 fev. 2016.

Claessens, S.; Feijen, E.; Laeven, L. "Political connections and preferential access to finance: the role of campaign contributions". Journal of Financial Economics, vol. 88, 2008. 
DUSCHINSKY, M. P. "Financing politics: a global view". Journal of Democracy, vol. 13, no 4, out. 2002.

GuARnieRI, F. "A força dos partidos 'fracos'". Dados, Rio de Janeiro, vol. 54, no 1, p. 235-258, 2011. Disponível em: <http://www.scielo.br/scielo.php?script=sci_arttext\&pid=S0011-

52582011000100007\&ln g=en\&nrm=iso >. Acesso em: 9 jan. 2016.

Gerber, A. "Estimating the effect of campaign spending on senate election outcomes using instrumental variables". American Political Science Review, vol. 92, no 2, jun. 1998.

HAIR, J., et al. Análise multivariada de dados. 5a ed. Porto Alegre: Bookman, 2005.

HeILER, J. G. Democracia: o jogo das incertezas $x$ financiamento de campanhas. Uma análise da prestação de contas das campanhas de vereadores de SC. Saarbrücken: Novas Edições Acadêmicas, 2014.

ISSACHAROFF, S.; KARLAN, P. S. "The hydraulics of campaign finance reform". Texas Law Review, no 77, p. $1.705-1.738,1998-1999$.

JACOBSON, G. C. "The effects of campaign spending in congressional election". The American Political Science Review, vol. 72, n² 2, p. 469-491, jun. 1978.

LAZZARINI, S. G.; et al. "What do development banks do? Evidence from Brazil, 2002-2009". Harvard Business School, Working Paper no 12-047, 2011. Disponível em:

<http://www.hbs.edu/research/pdf/12-047.pdf>. Acesso em: 5 nov. 2015.

MANCUSO W. P. "Investimento eleitoral no Brasil: balanço da literatura e agenda de pesquisa". Revista de Sociologia e Política, vol. 23, no 54, p. 155-183, jun. 2015.

MANCUSO, W. P.; SPECK, B. W. "O que faz a diferença? Gastos de campanha, capital político, sexo e contexto municipal nas eleições para prefeito em 2012". Cadernos Adenauer, vol. XIV, no 2, Candidatos, partidos e coligações nas eleições municipais de 2012. Rio de Janeiro: Fundação Konrad Adenauer, jun. 2013.

Peixoto, V. "Impacto dos gastos de campanhas nas eleições legislativas de 2010: uma análise quantitativa". Anais do $8^{\circ}$ Encontro ABCP, Gramado, RS, 2012.

POWER, T.; ZUCCO JR., C. "Elite preferences in a consolidating democracy". Latin American Politics and Society. 2012. Disponível em:

<http://www.fgv.br/professor/cesar.zucco/files/ArtigoLAPS2012.pdf>. Acesso em: 24 jun. 2015.

SAmUeLS, D. J. "Does money matter? Campaign finance in newly democratic countries: theory and evidence from Brazil". Comparative Politics, vol. 34, p. 23-42, 2001.

SANTOS, R. D. "O perfil de financiamento de campanha dos maiores grupos econômicos nas eleições de 2010. Anais da 36a Anpocs, GT 13. Águas de Lindoia, 2012.

SPECK, B. W. "Três ideias para oxigenar o debate sobre dinheiro e política no Brasil". Em Debate, Belo Horizonte, vol. 2, no 3, p. 6-13, mar. 2010.

. O financiamento político e a corrupção no Brasil. In: BIASON, R. C. (org.). Temas de corrupção política no Brasil. São Paulo: Balão Editorial, p. 49-97, 2012.

WELCH. W. P. "Campaign contributions and legislative voting: Milk money and dairy price supports". The Western Political Quarterly, vol. 35, no 4, p. 478-495, dez. 1982. 


\title{
Resumo
}

O custo da política subnacional: a forma como o dinheiro é gasto importa? Relação entre receita, despesas e sucesso eleitoral

Este artigo tem por objeto as despesas em campanhas eleitorais. Especificamente propõe: a) produzir um mapeamento dos gastos eleitorais da eleição de 2010 efetuados por candidatos a deputado federal; b) identificar padrões de gastos existentes; c) identificar a existência de correlação estatística importante entre diferentes padrões de gastos eleitorais e resultado eleitoral nas urnas. As questões que orientam o artigo são as seguintes: a) A forma como os atores utilizam seus recursos expressam as particularidades dos competidores? b) Determinados gastos de campanha possuem maior impacto no sucesso eleitoral do que outros? Para fins de mapeamento das despesas eleitorais elaborou-se uma classificação que busca apreender os gastos eleitorais em três grandes categorias: 1) gastos com "publicidade"; 2) gastos com "infraestrutura" de campanha; e 3) gastos com "pessoal". Os principais achados residem na percepção de que somente o volume de dinheiro não basta para explicar o sucesso eleitoral. Os modelos demonstram que o padrão de gasto precisa ser concentrado e que as maiores despesas devem ser destinadas para "comunicação e publicidade". Além disso, candidatos que disputam eleições em partidos mais organizados e com um grau de coordenação mais centralizado estão em melhores condições do que seus concorrentes que não compartilham dessa situação, conforme hipótese originalmente apresentada por Guarnieri (2011).

Palavras-chave: financiamento de campanhas; despesas eleitorais; deputado federal; eleições; prestação de contas eleitorais

\begin{abstract}
The cost of sub-national policy: How the money is spent is important? Relationship between funding, expenses and electoral success

The article focuses on spending on election campaigns. Specifically proposed: a) producing a mapping of election expenses of the 2010 election made by candidates to the House; b) Identify existing patterns of spending; c) Identify the existence of significant statistical correlation between different patterns of electoral spending and election results at the polls. The questions guiding the work are: a) how actors use their resources express the particularities of the contestants? b) certain campaign spending have greater impact on the electoral success than others? For purposes of mapping of election expenses has produced a classification that seek to apprehend election spending into three broad categories: 1) Spending on Advertising; 2) Spending on Infrastructure campaign; and 3) Personnel Expenses. The most important findings are the perception that only the amount of money is not enough to explain the electoral success. The models show that the spending pattern needs to be focused and that higher expenses are intended for communication and advertising. In addition, candidates who compete in elections better organized parties and with a degree of more centralized coordination are better than their competitors, as hypothesis originally presented by Guarnieri (2011).
\end{abstract}

Keywords: financing of campaigns; election expenses; federal deputy; elections; providing of electoral expenses

\section{Resumen}

El costo de la política subnacional: ¿La forma en que se gasta el dinero es importante? Relación entre los ingresos, los gastos y el éxito electoral

El artículo se centra en el gasto en campañas electorales. En concreto se propone: a) Producir un mapeo de los gastos electorales en las elecciones del año 2010 realizado por los candidatos al Congreso; b) identificar los patrones de gasto existentes; c) Identificar la existencia de una correlación estadística significativa entre los diferentes patrones de gastos electorales y resultados 
de las elecciones en las urnas. Las preguntas que guían el trabajo son las siguientes: a) ¿la forma en que los actores utilizan sus recursos expresa las particularidades de los competidores? b) ¿ciertos gastos de campaña tienen un mayor impacto en el éxito electoral que otros? Para efecto del mapeo de los gastos electorales se elaboró una clasificación que busca capturar los gastos electorales en tres amplias categorías: 1) El gasto en publicidad; 2) Los gastos en infraestructura de campaña; y 3) Los gastos de personal. Los principales resultados se encuentran en la comprensión de que sólo la cantidad de dinero no es suficiente para explicar el éxito electoral. Los modelos muestran que el patrón de gasto tiene que estar centrado y que los mayores gastos se destinan a la comunicación y la publicidad. Además, los candidatos que compiten en las elecciones con partidos más organizados y con un grado de coordinación más centralizada son mejores que sus competidores, como hipótesis desarrollada originalmente por Guarnieri (2011).

Palabras clave: financiación de la campaña; gastos electorales; miembro del Congreso; elecciones; prestación de los gastos electorales

\section{Résumé}

Le coût de la politique sous-nationale: La façon dont l'argent est dépensé est-elle importante? Le rapport entre les recettes, les dépenses et le succès électoral

Cet article met l'accent sur les dépenses de campagnes électorales. Plus précisément, il propose de: a) produire une cartographie des dépenses électorales des candidats à la Chambre des députés lors de l'élection de 2010; b) identifier les profils de dépenses; c) Déterminer l'existence d'une corrélation statistique significative entre les différents modèles de dépenses électorales et les résultats des élections dans les urnes. Les questions qui guident ce travail sont les suivantes: a) la façon dont les acteurs utilisent leurs ressources révèle-t-elle les particularités des concurrents? b) certaines dépenses de campagne ont-elles un impact plus important sur le succès électoral que d'autres? Quant à la cartographie des dépenses électorales, on a élaboré une classification qui cherche à appréhender les dépenses électorales en trois grandes catégories: 1) les dépenses de publicité; 2) Les dépenses de campagne en infrastructures; et 3) Les charges de personnel. Les principales conclusions émanent de la prise de conscience que la quantité d'argent ne suffit pas, à elle seule, à expliquer le succès électoral. Les modèles montrent que les profils de dépenses doivent être recentrés et les plus grandes dépenses destinées à la communication et à la publicité. En outre, les candidats aux élections, membres des partis les plus organisés et avec un degré de coordination plus centralisé, sont dans de meilleures conditions que leurs concurrents, selon I'hypothèse initialement présentée par Guarnieri (2011).

Mots-clés: financement de campagne politique; dépenses électorales; Congrès; élections; prestation de dépenses électorales 